Canadian

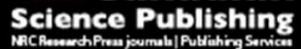

Canadian Journal of Forest Research Revue canadienne de recherche forestière

\title{
Even low levels of spruce budworm defoliation affect mortality and ingrowth but net growth is more driven by competition
}

\begin{tabular}{|r|l|}
\hline Journal: & Canadian Journal of Forest Research \\
\hline Manuscript ID & cjfr-2017-0012.R3 \\
\hline Danuscript Type: & Article \\
\hline Complete List of Authors: & $\begin{array}{l}\text { CHEN, CEN; University of Maine, School of Forest Resources } \\
\text { Weiskittel, Aaron; University of Maine } \\
\text { Bataineh, Mohammad; University of Arkansas at Monticello, } \\
\text { MacLean, David; University of New Brunswick, }\end{array}$ \\
\hline $\begin{array}{r}\text { Is the invited manuscript for } \\
\text { consideration in a Special } \\
\text { Issue? : }\end{array}$ & growth, mortality, ingrowth, spruce budworm, defoliation \\
\hline
\end{tabular}

SCHOLARONE ${ }^{\mathrm{m}}$

Manuscripts 
1 Even low levels of spruce budworm defoliation affect mortality and ingrowth but net 2 growth is more driven by competition

3 Cen Chen $^{1}$, Aaron Weiskittel ${ }^{2}$, Mohammad Bataineh $^{3}$, and David A. MacLean ${ }^{4}$

$4 \quad{ }^{1}$ University of Maine, School of Forest Resources, Orono, ME 04469, cen.chen@maine.edu

$5 \quad 2$ University of Maine, School of Forest Resources, Orono, ME 04469,

6 aaron.weiskittel@maine.edu

$7 \quad{ }^{3}$ University of Arkansas System Division of Agriculture, Agricultural Experiment Station-

8 University of Arkansas at Monticello, School of Forestry \& Natural Resources, Monticello,

$9 \quad$ AR 71655, Bataineh@uamont.edu

$10{ }^{4}$ University of New Brunswick, Faculty of Forestry and Environmental Management, P.O.

11 Box 4400, Fredericton, NB, E3B 5A3 Canada, macleand@unb.ca

12 Corresponding Author:

13 Aaron Weiskittel

145755 Nutting Hall

15 University of Maine

16 Orono, ME 04469-5755

$17 \quad 207-581-2857$ (phone)

$18 \quad 207-581-2875$ (fax)

19 aaron.weiskittel@maine.edu 


\section{Abstract}

Defoliation reduces the growth and survival of trees, but this influence can be difficult to evaluate largely because of its interplay with various stand and site factors, especially for the highly dynamic defoliation of spruce-fir (Picea-Abies) forests caused by spruce budworm (SBW; Choristoneura fumiferana (Clem.)), the primary tree defoliator in North America. In this study, we developed statistical models to evaluate the influence of SBW defoliation, while considering its interaction with various stand and site factors, on spruce-fir stand dynamics of annual volume net growth, mortality, and ingrowth. The data were collected at 1-3 years intervals from 560 permanent sample plots during the last SBW outbreak (1970s1980s) in Maine, USA and New Brunswick, Canada. These data comprise a wide range of observations of cumulative defoliation, especially at relatively low levels, which have been largely overlooked in previous studies. Our results strongly demonstrated that even relatively low levels of cumulative defoliation were significantly related to stand-level mortality and ingrowth, while net growth was more competition driven. Additionally, these stand dynamics were found not significantly affected by any of the site factors evaluated. These findings were consistent for Maine and New Brunswick despite their differences in forest management and SBW outbreak histories.

37 Keywords: growth, mortality, ingrowth, spruce budworm, defoliation 


\section{Introduction}

Loss of photosynthetic material through insect defoliation results in reduced growth and survival of trees, and is one of the most important natural disturbances influencing forests (e.g., Kulman 1971, MacLean 2016). Spruce budworm (SBW; Choristoneura fumiferana (Clem.)) is the primary defoliating insect in North America and has affected over 58 million ha of forests during its last major outbreak in 1970s and 1980s (Blais 1983, USDA Forest Service 2009). Consequently, approximately 44 million $\mathrm{m}^{3}$ of timber was lost annually during this outbreak period in Canada alone (Sterner and Davidson 1982). On the other hand, SBW has co-evolved with spruce-fir (Picea-Abies) forests for hundreds of years with periodic outbreaks 30-60 years apart (Fraver et al. 2007), and these forests are still abundant in the region (McWilliams et al. 2005, Power and Gillis 2006). Therefore, evaluating the influence of SBW defoliation on stand dynamics is critical in predicting future supply of forest products and in understanding stand dynamics and succession under varying disturbance regimes.

SBW larval emergence is synchronized with the bud burst of its hosts balsam fir (Abies balsamea L.) and white spruce (Picea glauca (Moench) Voss), and these larvae feed primarily on current year foliage despite the species' retention of multiple years of foliage (Irland et al. 1988). Additionally, SBW defoliation has cumulative effects on growth and mortality. For example, Blais (1958) noted that growth reduction was often observed after two years of defoliation, while MacLean (1980) suggested that trees usually started to die only after four or five years of severe defoliation. Consequently, cumulative sums of the defoliation of current-year foliage (cumulative defoliation) have long been considered a suitable metric in measuring the severity of SBW defoliation.

There is a vast literature on the influence of SBW defoliation on forest development

(e.g., Blais 1958, MacLean 1980, Osawa et al. 1986, Reams et al. 1988, MacLean and Ostaff 
1989, Piene 1989, MacLean et al. 1996, Solomon et al. 2003, Pothier and Mailly 2006,

Pothier et al. 2012), with reported tree mortality between $73-100 \%$ for balsam fir and between $27-66 \%$ for spruce (Picea spp.) and growth reductions in balsam fir up to $83 \%$. The cumulative defoliation that caused the above mortality and growth reductions have largely ranged between 336-840\% (Blais 1958, MacLean and Ostaff 1989, Piene 1989, MacLean et al. 1996). Obviously, the influence of SBW defoliation on forest development has generally been assessed at rather high levels of defoliation, and was largely overlooked for cumulative defoliation levels below 300\%.

Furthermore, studies on SBW defoliation have often been confined in space (1-73 sample plots; Blais 1958, MacLean 1980, Reams et al. 1988, MacLean and Ostaff 1989, Piene 1989, MacLean et al. 1996, and Solomon et al. 2003) or rather coarse in temporal resolution ( $\sim 10$ years between measurements; Pothier and Mailly 2006, Pothier et al. 2012). Hence, their representativeness of the dynamic process of defoliation hinged on the premise that this process was comparable at various spatial and temporal scales. However, defoliation is heterogeneous and varies greatly over space and time during a SBW outbreak (Supplemental Materials S1, Baskerville and MacLean 1979, Irland et al. 1988, Hennigar et al. 2013). Consequently, the influence of SBW defoliation on forest development is also likely to be heterogeneous at different scales. For example, Osawa et al. (1986) was restricted to a portion of Baxter State Park $\left(\sim 800 \mathrm{~km}^{2}\right)$ in Maine and recorded mortality for balsam fir from mid-1970s to 1982 of 74\%, while Brann et al. (1985) summarized data from across northern Maine ( $>40000 \mathrm{~km}^{2}$ ) during the same period and reported such mortality of $\sim 15 \%$. Therefore, it is critical to evaluate whether this influence is an artifact of scaling of the defoliation process, or is consistent over large areas.

Besides the high variation in defoliation, evaluating the influence of SBW defoliation on forest development is challenging because forest stand and site characteristics, which are 
indicators of resource availability (productivity) and competition, are also expected to vary considerably within the vast areas affected by SBW defoliation. While productivity and competition regulate forest development in the absence of disturbances, they most likely interact with defoliation and confound their effects on forest development. For example, while defoliation directly reduces tree growth, it may also cause mortality of the neighboring trees and hence reduce competition and promote growth of the surviving trees. On the other hand, some stand and site characteristics may be favorable to SBW, e.g., a higher content of a preferred host, thus intensifying the influence of defoliation. Therefore, evaluating the influence of SBW defoliation and its potential interactions with a variety of stand and site characteristics is necessary to provide a more comprehensive understanding of the influence of defoliation. Identifying the relative importance of productivity, competition, and defoliation in forest development is critical for prioritizing forest management activities to address the influence of defoliation.

This study utilized comprehensive defoliation data collected at short time intervals (13 years) from extensive networks of permanent sample plots (PSP; 560 in total) that covered a longitudinal range of $\sim 490 \mathrm{~km}$ and a latitudinal range of $\sim 340 \mathrm{~km}$. These data comprised a wide range of cumulative defoliation observations accompanied by detailed tree and site measurements, which provided opportunities to evaluate how varying levels of SBW defoliation (especially lower levels that have been largely overlooked in previous studies) influenced forest development, and to assess how the effects of defoliation on growth, mortality, and ingrowth interacted with stand and site characteristics. The above data were used to quantify the influence of SBW defoliation on key forest stand dynamics since stand development is considered the linkage between pest incidence and forest development (Erdle and MacLean 1999) and evaluating stand dynamics generally requires less information (Weiskittel et al. 2011a). This analysis was applied separately to two rather distinct regions 
with contrasting forest management and SBW outbreak histories to test whether it was valid and consistent over a broad geographical area with varying stand, site, and defoliation conditions.

Specific research objectives were to: 1) model annual stand volume net growth, mortality, and ingrowth using variables derived for SBW defoliation, stand structure and composition, potential productivity, and topography from long-term, remeasured permanent plots across both of the regions; 2) evaluate the varying influences of SBW defoliation and identify the most important stand and site factors on the above variables of stand dynamics; and 3) perform the above modeling and evaluation in Maine and New Brunswick, which differ in forest management and SBW outbreak histories, to better verify the robustness and consistency of our findings. It was expected that our findings would indicate that defoliation, even at relatively low levels, had an important role in all of the stand dynamic variables examined, but this effect would depend largely on stand structure and composition as well as important site factors like soil drainage. In addition, our models were expected to indicate these effects of defoliation, as well as its interaction with stand and site characteristics, were comparable between the two regions, despite differences in their forest management and SBW outbreak histories. This would provide support to the general robustness and consistency of the models.

\section{Material and Methods}

\subsection{Study Area}

The combined study area $\left(44^{\circ} 56^{\prime}-48^{\circ} 00^{\prime} \mathrm{N}, 64^{\circ} 28^{\prime}-70^{\circ} 44^{\prime} \mathrm{W}\right)$ in Maine and New Brunswick mainly belongs to the temperate broadleaf mixed forest biome (Figure 1). The most common forest types in Maine include maple-beech-birch (Acer-Fagus-Betula) of 2.9 million ha and spruce-fir of 2.4 million ha in 2003 (McWilliams et al. 2005). Growing stocks of SBW's major hosts of balsam fir, red spruce (Picea rubens Sarg.), black spruce (Picea 
138 mariana (Mill.) B.S.P.), and white spruce were 117, 146, 14, and 17 million $\mathrm{m}^{3}$, respectively, 139 in 1982, and 65, 100, 15, and 17 million $\mathrm{m}^{3}$, respectively, in 2003 (McWilliams et al. 2005).

140 New Brunswick had 2.5, 1.8, and 1.4 million ha of softwood, mixedwood, and hardwood

141 forests, respectively, in 2001 (Power and Gillis 2006). Growing stock of balsam fir and

142 spruce was 118 and 154 million $\mathrm{m}^{3}$, respectively, in 1981 , and 91 and 174 million $\mathrm{m}^{3}$, respectively, in 2001 (Bonnor 1982, Power and Gillis 2006). Soils in Maine and New

Brunswick are generally infertile, acidic, and low in permeability (Ferwerda et al. 1997; Rees et al. 2005). Maine has a humid continental climate with warm, humid summers, and cold, snowy winters. Annual precipitation varies from 909 to $1441 \mathrm{~mm}$ and is distributed evenly year-round. Climate in New Brunswick is similar to that of Maine with annual precipitation ranging from 889 to $1143 \mathrm{~mm}$, evenly distributed through the year. Elevation of the study areas in Maine and New Brunswick ranged from 41-691 m and 0-578 m, respectively. These two areas have similar SBW outbreak histories as both experienced an outbreak in the 1970s1980s.

\subsection{Data}

The data used in this study came from the University of Maine Cooperative Forestry Research Unit Growth Impact Study data collected in northern Maine, USA (Solomon and Brann 1992) and Canadian Forest Service permanent sample plots data collected in New Brunswick, Canada (MacLean and Erdle 1986). The most significant difference between the two regions in the data was species composition, which Fraver et al. (2007) considered to be the reason behind the differences in their SBW outbreak histories, in addition to the dynamics of SBW outbreaks. Specifically, balsam fir, red spruce, black spruce, white spruce, and hardwood accounted for $37 \%, 23 \%, 2 \%, 3 \%$, and $19 \%$ of all trees in stems, respectively, in Maine, and $37 \%, 21 \%, 11 \%, 9 \%$, and $14 \%$ of all trees in stems, respectively, in New Brunswick. Each of the datasets used in this study is described in detail below. 


\subsubsection{Growth Impact Study of Maine}

The Growth Impact Study was initiated in 1975 (after SBW activity reached epidemic level in 1974) as a cooperative effort among federal and state forest agencies, as well as private forestry companies to document the impact of SBW on growth and mortality of the Maine forest. Data were collected at $424 \sim 0.2$ ha circular plots including 8762 trees $\geq 11.4$ cm in diameter at breast height (DBH) throughout northern Maine during 1975-1985 (most of the temporal extent of the last SBW outbreak in Maine). The data included annual records of species, DBH, crown position, cause of death, total height, crown length, and degree of defoliation. Each year during the study period, current-year and previous-years foliage on each host tree within the plot were visually examined for the degree of defoliation, and categorized separately into one of five classes (before 1982; 0, 1-5\%, 6-20\%, 21-50\%, and $51-100 \%$ ) or eleven classes (after 1982; 0-10\%, 11-20\%, 21-30\%, 31-40\%, 41-50\%, 51-60\%, $61-70 \%, 71-80 \%, 81-90 \%, 91-99 \%$, and $100 \%$ ) of defoliation.

\subsubsection{Permanent Sample Plots of New Brunswick}

Approximately 1500 random PSPs were established between 1976-1979 as part of the New Brunswick Department of Forests, Mines and Energy Forest Inventory. Of these plots, 136 were selected for SBW related studies based on stratification by species, maturity, and degree of insecticide use for protection. Each PSP consisted of three permanent prism points (basal area factor $=2 \mathrm{~m}^{2} \mathrm{ha}^{-1}$ ) located $40 \mathrm{~m}$ apart, on which species, DBH, crown class, year of death, initial height, and degree of defoliation of each tree were recorded. The above data were collected during 1976-1993, with DBH initially measured between 1976 and 1979 and remeasured in 1980, 1983, 1985, 1988, and 1991. Current year and total defoliation (defoliation on all age classes of foliage) were measured annually during 1984-1993 (when the SBW outbreak was declining), while height was measured once during 1976-1979. For all of the 6316 sample trees in the PSP data set, only the 5503 trees compatible in size with the 
188 Growth Impact Study dataset (i.e. $\mathrm{DBH} \geq 11.4 \mathrm{~cm}$ ) were included in this study. Both current-

189 year and total defoliation in the New Brunswick PSPs was estimated for each host tree each

year by scanning the crowns with binoculars. The results of both types of defoliation were separately put into seven percentage classes of $0-10 \%, 11-20 \%, 21-40 \%, 41-60 \%, 61-80 \%$, $81-99 \%$, and $100 \%$.

\subsubsection{Data Compilation}

All measurements in the two datasets were converted to metric units. Since annual measurements of DBH were not available for the PSP dataset, spline and linear functions were used to impute DBH values for years between measurements. Height values for the PSP dataset were obtained through imputation using a species- and plot-specific mixed effects model outlined by Robinson and Wykoff (2004). Given the difficulty in accurately measuring heights on an annual basis, height increments of $>0.9 \mathrm{~m} \mathrm{yr}^{-1}$ in the Growth Impact Study dataset ( $1.1 \%$ of the total observations) were replaced by values obtained using the above modeling approach. All individual tree total volumes were estimated using a species-specific taper equation for the region ( $\mathrm{Li}$ et al. 2012; Weiskittel and Li 2012). As SBW prefers sun foliage and hence causes frequent top-kill (Ostaff and MacLean 1989), tree height increment was greatly reduced and nearly ceased from the beginning of our data. Therefore, top-kill was an implicit factor in consecutive measurements of height, which were inputs to the taper equation that was used to predict consecutive volumes. Consequently, top-kill likely had a minimal effect in predicting volume growth, which was derived by subtracting these consecutive predictions of volume.

At the plot-level, several attributes describing structure and composition were derived. Stand density index was estimated using the additive method and relative density values were computed using an equation proposed by Woodall et al. (2005) that predicts maximum stand density index using average species specific gravity (USDA 2010). Preliminary analysis 
213 indicated that this measure of relative density outperformed more traditional stand structural metrics like stem density and total basal area. Additionally, stand species composition was represented by the proportions of balsam fir (BF), black spruce (BS), red spruce (RS), white spruce (WS), and hardwood species (HW). Site productivity was estimated through dominant height and several other metrics including biomass growth index (Hennigar et al. 2017), climate site index (Weiskittel et al. 2011b), topographic wetness index, and other site attributes like slope, aspect, and elevation as well as their transformations (Stage 1976).

A variety of defoliation metrics were evaluated including those presented in Hennigar et al. (2013). For this analysis, severity of defoliation was presented as cumulative sums of the percentage defoliation of current-year foliage from all previous years until current year, which was rather commonly used in previous studies and the most effective metric indicated by our preliminary analysis. The observed cumulative defoliation varied between $0-586 \%$ and averaged $85 \pm 86 \%$ (mean $\pm \mathrm{SD}$ ) and $64 \pm 53 \%$ in Maine and New Brunswick, respectively. Cumulative defoliation was primarily concentrated towards the lower end of the above range in the data. Specifically, there were $3250,935,295$ and 119 stand-level observations of 0$100 \%, 101-200 \%, 201-300 \%$, and $>300 \%$ defoliation, respectively. Although the defoliation levels were generally lower than reported in previous studies, a large range of defoliation values observed and the wider geographic region examined may explain these trends. In addition, as described below, both areas had varying levels of aerial spraying of insecticide.

During the last outbreak, portions of both regions underwent aerial spraying of insecticide against SBW. This protection activity included most of New Brunswick's forested areas in certain years (MacLean et al. 1984). From 1970 to 1974, an average of 160000 ha of forests was sprayed annually in Maine. This resulted in nearly $17 \%$ of the Growth Impact Study plots being sprayed at least once during this period. As the spraying extended to over 400000 ha year $^{-1}$ through the outbreak, and peaked at 1.6 million ha in 1976 (Seegrist and Arner 1982), it is reasonable to assume that the majority of these plots received some 
spraying. However, preliminary analysis found no identifiable relationships between spraying and the examined stand dynamics, so additional analyses using information on spraying were not explored further (Supplemental Materials S2). Likely, the effects of spraying are implicitly accounted for in the observed cumulative defoliation values, which would have been probably higher without spraying.

For this analysis, several components of stand dynamics, namely, annual volume net growth, mortality, and ingrowth were included. Values of standing volume, mortality, and ingrowth were derived by summing the per ha volumes of each tree at each measurement period by status (live, dead, or ingrowth). Ingrowth was defined as all (host and non-host) trees $\geq 11.4 \mathrm{~cm} \mathrm{DBH}$ that were not present in the previous measurement. Since trees in the understory are more sensitive to defoliation and often die first during an outbreak (Blais 1958), defoliation was expected to directly affect ingrowth, while the plot-level cumulative defoliation was considered a suitable representation of understory defoliation severity. The response variable of annual volume net growth was obtained by subtracting subsequent standing volume from the previous one (volume increment of surviving trees); and the response variables for annual volume mortality and ingrowth were taken as the percentage of corresponding standing volume. For the variable-radius plots in the NB PSP dataset, tree expansion factors at the first measurement were fixed for subsequent measurements to ensure compatibility as suggested by Myers and Beers (1968). A summary of the attributes derived from the data used in this analysis is presented in the Supplemental Materials S3.

\subsection{Analysis}

The above response variables were related to various stand structure, species composition, site productivity, and defoliation variables, and fitted with nonlinear mixed effect models by setting a random effect across plots. Model selections (of suitable model formulations and predictors) were based on a combined consideration of biological 
264 interpretability, Akaike Information Criterion (AIC), coefficient of determination $\left(\mathrm{R}^{2}\right)$, and

265 mean bias (predicted - observed). The selected models best depicting stand dynamics in

266 response to defoliation are all described in more detail below. All analyses were conducted in

267 R v3.2.2 (R Development Core Team 2015). In particular, the R package "nlme" (Pinheiro et

al. 2016) was used for constructing the nonlinear mixed effect models.

269

270

271

272

273

274

275

276

277

278

279

280

281

282

283

\subsubsection{Net Growth}

In general, the growth of trees likely exhibits a sigmoidal behavior, which both

logistic and Gompertz functions are suitable to model this expected trend. A major difference between these two functions lies in that logistic and Gompertz functions reach their inflection points (maximum acceleration in growth) at $K / 2$ ( $K$ is the asymptote in yield) and $K / e$, respectively. The latter better matches the relatively short period of accelerated growth of trees in their early stage, and can be parameterized as follows:

$$
\text { (1) } y(t)=K \exp \left(\ln \left(\frac{y(0)}{K}\right) \exp (-r t)\right)
$$

where $y(t)$ is the yield at time $t ; K, y(0)$, and $r$ are parameters, of which $K$ is the asymptote of yield, $y(0)$ is the initial volume, and $r$ is the growth rate.

Differentiating Equation (1) on $t$, substituting functions of $t$ with Equation (1) so to avoid explicitly including time $t$ as a covariate (since its relationship with growth may be distorted by forest management activities and disturbances like SBW), and expanding $K$ and $r$ such that the former is density dependent and the latter is affected by potential productivity ( $\beta 4)$, species composition ( $\beta 3, \beta 5$, and $\beta 7)$, and defoliation ( $\beta 5$ and $\beta 7$ ) generates the following growth function: 


$$
\begin{aligned}
& \text { (2) } y^{\prime}(t)=y(t) \ln \left(\frac{K}{y(t)}\right) r \\
& =y(t) \ln \left(\frac{\exp ((\beta 1+\gamma 1)+\beta 2 \cdot R D)}{y(t)}\right)\left(\begin{array}{c}
\beta 3 \cdot \exp (B S+R S+W S) \cdot H W \\
+\beta 4 \cdot H T_{D O M} \\
+\beta 5 \cdot(B S+R S+W S) \cdot C D E F+\beta 6 \cdot B F \\
+\beta 7 \cdot B F \cdot C D E F
\end{array}\right)+\varepsilon
\end{aligned}
$$

284 where $y^{\prime}(t)$ is net growth at time $t\left(\mathrm{~m}^{3} \mathrm{ha}^{-1} \mathrm{yr}^{-1}\right) ; R D$ is relative density; $B F, B S, R S, W S$, and $H W$ are proportions of balsam fir, black spruce, red spruce, white spruce, and hardwood in terms of volume, respectively; $H T_{D O M}$ is dominant height (m); $C D E F$ is cumulative defoliation (\%); $\beta 1$ - $\beta 7$ are parameters for fixed effects ( $\beta 7$ was not applied to the New Brunswick data); $\gamma 1$ is a parameter for plot-level random effect; and $\varepsilon$ is the error of the model. Since considerable variation was found in $K$ and the standard deviation of $r$ was less than $0.01 \%$ of its mean in both datasets, only random effects for the intercept of $K(\beta 1)$ were considered in the models.

\subsubsection{Mortality}

Zero-inflated models have been used for modeling rare events like tree mortality, and were tested in this analysis in both frequentist and Bayesian settings assuming a beta distribution for mortality/ingrowth (as the ratio between mortality/ingrowth volume and standing volume expressed as a percentage through this analysis; Supplemental Materials S4). It was found that these models yielded fewer close-to-zero predictions for actual zero observations and smaller predicted values for over-dispersed observations than the models proposed below.

Consequently, to address both excessive zeros and over-dispersion in the observations, a model of $\%$ mortality in volume of the following form, which had a goodness-of-fit at least as good as the zero-inflated models, was used:

$$
\text { (3) } y=\frac{1}{1+\exp \left(-\left(\begin{array}{c}
\beta 1+\gamma 1 \\
+\beta 5 \cdot H T_{D O M}
\end{array}\right)\right)} \cdot \frac{1}{1+\exp \left(-\left(\begin{array}{c}
\beta 6+\beta 2 \cdot B F \cdot C D E F+\beta 3 \cdot V O L \\
+\beta 4 \cdot(B S+R S+W S) \cdot C D E F
\end{array}\right)\right)}
$$


where $V O L$ is standing volume $\left(\mathrm{m}^{3} \mathrm{ha}^{-1}\right) ; \beta 1-\beta 6$ are parameters for fixed effects $(\beta 4-\beta 6$ were not applied to the New Brunswick data); $\gamma 1$ is a parameter for random effect; and the other notations are the same as defined above. Equation (3) can be considered as a modification of the zero-inflated model in that $1 / 1+\exp \left(-\left(\beta 1+\gamma 1+\beta 5 \cdot H T_{D O M}\right)\right)$ can be treated as the probability of belonging to the distribution of actual mortality values in a zeroinflated model. However, the mass of zeros were removed from the parameter estimation of a zero-inflated model (so mortality estimated using Equation (3) would not be reduced by a $<1$ probability of not being zero) to allow for more dispersed estimates. Preliminary analysis showed significant effect of $V O L$ on mortality independent of stand development stage, such that mortality rate monotonously decreased over the increase of various formulations of $V O L$, of which the one used in Equation (3) was highly significant and most parsimonious.

\subsubsection{Ingrowth}

The ingrowth data and the modeling approach for it shared common features with mortality. However, an even greater number of zeros was observed in ingrowth (87\% of plot observations), which also exhibited a higher level of variability than mortality. In this case, the probability of belonging to the distribution of actual ingrowth values as in Equation (3) practically went to zero in the modeling process. For this reason, \% ingrowth in volume was modeled using a single logistic function as follows:

$$
\text { (4)y }=\frac{1}{1+\exp \left(-\left(\begin{array}{c}
\beta 1+(\beta 2+\gamma 2) \cdot B F \cdot C D E F+\beta 3 \cdot H T_{D O M} \\
+(\beta 4+\gamma 4) \cdot V O L+\beta 5 \cdot(B S+R S+W S)
\end{array}\right)\right.}+\varepsilon
$$

where $\beta 1-\beta 5$ are parameters for fixed effects ( $\beta 3$ and $\beta 5$ were not applied to the New Brunswick data); $\gamma 2$ and $\gamma 4$ are parameters for random effects; and the other notations are the same as defined above. Similar to the mortality model, ingrowth rate monotonously decreased over the increase of various formulations of $V O L$, of which the one used in 
325 Equation (4) was highly significant and most parsimonious.

\section{3. Results}

\subsection{Net Growth}

Models for annual volume net growth (volume increment of surviving trees) as well as mortality and ingrowth were built using 3846 and 753 observations for Maine and New Brunswick, respectively. The fixed effects of the net growth models explained 64 and $64 \%$ (79 and $88 \%$ when random effects were also considered) of its variation for Maine and New Brunswick, respectively. The mean predicted net growth was 3.79 and $5.43 \mathrm{~m}^{3} \mathrm{ha}^{-1} \mathrm{yr}^{-1}$ with mean biases (predicted - observed) of +0.09 and $+0.07 \mathrm{~m}^{3} \mathrm{ha}^{-1} \mathrm{yr}^{-1}$ for Maine and New Brunswick, respectively. All parameter estimates were significant at $\mathrm{p}<0.05$ level (except for $\beta 5$ in the New Brunswick model), and strictly in accordance in direction, comparable in magnitude and relative importance, and ecological interpretability for the two regions (Table $1)$.

Our analysis showed an inverse relationship between net growth and defoliation, and this relationship was dependent on the proportion of host species in that net growth was significantly lower with higher spruce and balsam fir content (Table 1). Specifically, when cumulative defoliation increased from 100 to $200 \%$, net growth decreased from 3.43 to 3.00 $\mathrm{m}^{3} \mathrm{ha}^{-1} \mathrm{yr}^{-1}$ (equivalent to a relative decrease of $13 \%$ ), while a 0.1 increase in the proportion of spruce and hardwood content decreased net growth by 0.03 and $0.15 \mathrm{~m}^{3} \mathrm{ha}^{-1} \mathrm{yr}^{-1}$, respectively, without the influence of defoliation (cumulative defoliation equals zero) in Maine. In addition, none of the site factors tested significantly affected net growth. Net growth was predominantly controlled by stand density (indicated by relative density and standing volume) and potential productivity (indicated by dominant height), while moderately influenced by defoliation and species composition during a SBW outbreak (Figure 2). 
Similar results were found in New Brunswick, where the same specific growth reductions as shown above were from 4.89 to $4.52 \mathrm{~m}^{3} \mathrm{ha}^{-1} \mathrm{yr}^{-1}$ (equivalent to a relative decrease of $8 \%$ ) due to the increase in defoliation as well as 0.04 and $0.34 \mathrm{~m}^{3} \mathrm{ha}^{-1} \mathrm{yr}^{-1}$ related to the increases in spruce and hardwood content. Furthermore, the above relationships were presented at the mean values of the other variables in these nonlinear models, and consistent between the two regions, although both the observed and predicted net growth was generally higher in New Brunswick than in Maine (Supplemental Materials S3 and Figure 3).

\subsection{Mortality}

A total of $28 \%(47 \%)$ and $34 \%(54 \%)$ of the variation in annual volume mortality rate was explained by the fixed effects (and random effects) in the models for Maine and New Brunswick, respectively. The mean predicted annual volume mortality rate was $2.32 \%$ and $1.83 \%$ with mean biases of -0.10 and $+0.14 \%$ for Maine and New Brunswick, respectively. All parameter estimates were significant at $\mathrm{p}<0.01$ level, and consistent in direction, magnitude, relative importance, and ecological interpretability between the two regions (Table 2).

Both observed and predicted mortality rates were relatively low, even under the higher levels of defoliation observed across the regions (Supplemental Materials S3 and Figure 4; defoliation was generally lower in this study compared to previous studies). Besides decreasing with an increase in standing volume and reduction in host content, mortality rate was most sensitive to defoliation, especially in Maine (Figure 2). Specifically, when cumulative defoliation increased from 100 to $200 \%$, annual mortality rate increased from 1.9 to $3.8 \%$ and from 1.7 to $2.1 \%$ in Maine and New Brunswick, respectively, which were equivalent to relative increases of 101 and $23 \%$, respectively. There was also a slight difference in the response of mortality rate to the increase of the various host species such that a 0.1 increase in the proportion of balsam fir and spruce content increased annual 
mortality rates by 0.27 and $0.26 \%$, respectively, at $100 \%$ cumulative defoliation in Maine.

Furthermore, the above relationships were presented at the mean values of the other variables in the nonlinear models, and consistent between the two regions (Supplemental Materials S3 and Figure 4).

\subsection{Ingrowth}

Models for annual volume ingrowth rate accounted for 20\% (33\%) and 21\% (37\%) of its variation by the fixed effects (and random effects) for Maine and New Brunswick, respectively. The mean predicted annual volume ingrowth rate was $0.42 \%$ and $0.59 \%$ with mean biases of $\sim 0.00 \%$ and $+0.13 \%$ for Maine and New Brunswick, respectively. All parameter estimates were significant at $\mathrm{p}<0.01$ level (except for $\beta 2$ in the New Brunswick model). The effects of all of the covariates were comparable across the regions, and consistent with ecological expectations (Table 3).

Both observed and predicted ingrowth rates were low across the regions, although consistently higher in New Brunswick than in Maine (Supplemental Materials S3 and Figure 5). The factors of defoliation, proportion of host species, standing volume, and dominant height all appeared to negatively affect ingrowth rate (Table 3) with the first two factors being most influential (Figure 2). In particular, when cumulative defoliation increased from 100 to $200 \%$, annual ingrowth rate would decrease from 0.14 to $0.12 \%$ and from 0.48 to $0.39 \%$ in Maine and New Brunswick, respectively, which were equivalent to relative decreases of 15 and $18 \%$, respectively. In addition, the above relationships were presented at the mean values of the other variables in the nonlinear models, and consistent between the two regions (Supplemental Materials S3 and Figure 5).

\section{Discussion}

Defoliation, despite being generally lower in this study when compared to previous studies, was found to have a significant influence on all of the stand dynamic responses 
examined. Consistent with our initial expectations, these influences of defoliation were found to be most dependent on stand species composition, with balsam fir stands experiencing higher levels of growth reduction and mortality, and less ingrowth than spruce stands. As cumulative defoliation increased from 0 to $100 \%$, net growth reduction averaged 0.90 and $0.67 \mathrm{~m}^{3} \mathrm{ha}^{-1} \mathrm{yr}^{-1}$ for stands with $75 \%$ balsam fir and $25 \%$ hardwood versus $75 \%$ spruce and $25 \%$ hardwood, respectively. Although these reductions in net growth were only moderate, it is a bit surprising that cumulative defoliation at such a low level had any significant effect. Since our models showed much higher normal growth rates of balsam fir than spruce or hardwood species, and the difference in net growth reduction influenced by defoliation between balsam fir and spruce stands was small, balsam fir dominated stands would likely maintain relatively higher rates of growth when compared to spruce dominated stands under the same levels of defoliation. This agreed with the higher growth rates of balsam fir mixed stands than spruce mixed stands following SBW defoliation reported by Colford-Gilks et al. (2012). However, both Hennigar et al. (2008) and our analysis indicated that balsam fir tended to experience higher levels of defoliation (i.e. more susceptible) than spruce species. Many studies mentioned above have reported the influence of defoliation on mortality of individual trees by species, which ranges from $73-100 \%$ for balsam fir and 27 $66 \%$ for spruce species under $336-840 \%$ cumulative defoliation. There was no obvious way to directly compare these tree-level statistics with our stand-level estimates that were conditional on a variety of characteristics. However, it was likely that our mean predicted annual volume mortality rates of 2.32 and $1.83 \%$, which are approximately equivalent to tenyear cumulative mortality rates of 21 and $17 \%$ for Maine and New Brunswick, respectively, were below those reported by studies identified above. The relatively low mortality rates in this study were likely related to the mean observed cumulative defoliation of 85 and $64 \%$ for Maine and New Brunswick, respectively, which could also be a major cause behind the discrepancy in mortality between this study and some previous studies. It was also found in 
426 this study that both observed and predicted mortality rates decreased with the increase in

standing volume. A test of the interaction between standing volume and relative density confirmed this effect of standing volume on mortality for a given relative density, as well as indicated that mortality rate and relative density were positively related for a given standing volume.

Several limitations that influence interpretation of our findings should be recognized. First, the temporal extent of our data did not cover the full duration of the last SBW outbreak. SBW activity reached epidemic levels in 1974 in Maine (Irland et al. 1988), but the data began in 1975. The New Brunswick SBW outbreak spanned 1965-1993 in different parts of the province, and the analysis period in this study was 1986-1991, which was when SBW populations and defoliation were declining. Second, the effect of insecticide spraying was tested based on spraying records of the sample plots in Maine during 1970-1974 and found to be highly insignificant in this analysis (Supplemental Materials S2). MacLean et al. (1984) also found that spraying did not significantly change mortality rates of black and red spruce. Likely, the effects of spraying were essentially captured in our cumulative defoliation data, which would have been higher if spraying had not been conducted. Third, sampling differences occurred between the two datasets, such as the use of variable-radius sampling in New Brunswick versus fixed-area plots in Maine. However, such sampling inconsistencies were likely small in comparison to the observed effects of defoliation as well as the broad spatial and temporal span of the sample plots.

The stand dynamics examined in this study exhibited a large amount of variation, with coefficients of variation (CV) for annual volume mortality and ingrowth of 277 and $331 \%$ for Maine, and 188 and 329\% for New Brunswick, respectively. This was much higher than the 11\% CV of mortality from Cape Breton Island, Canada (e.g., MacLean and Ostaff 1989), which had uniformly high mortality (mean $87 \%$ ) caused by severe defoliation. Observed variations in these stand dynamic responses were higher than those usually associated with 
452 typical stands. Consequently, relationships between these responses and site characteristics

were not significant and none of the characteristics examined accounted for more than $1 \%$ of the variation in the response variables in either of the regions (Supplemental Materials S5). This observation is in agreement with MacLean et al. (1984) and MacLean and MacKinnon (1997), who found spruce-fir growth and mortality were not related to site characteristics, and could suggest that the effects of site characteristics found on SBW defoliation caused growth reduction and mortality (e.g., Blais 1958, Osawa et al. 1986) may have been location specific as in reflecting local limiting factors on growth and mortality.

A considerable amount of variations in stand dynamics was accounted for by random effects among sample plots in our models. This could be an indication of important factors affecting stand dynamics not being included in the models. However, this is less likely given that many common stand and site factors were tested and failed to show statistically significant relationships. It therefore was more likely that the random effects reflected autocorrelation in stand dynamics. Spatial clustering of mortality over a small extent found in this study and reported by Baskerville and MacLean (1979) could reflect this autocorrelation. Inclusion of a spatial or temporal autocorrelation error structure did not improve model fit significantly. Likely, a complex and dedicated research effort involving a denser sample plot network over a broader area and a longer time series would be necessary to fully investigate this potential autocorrelation.

The same models fit the data from both Maine and New Brunswick well, with parameter estimates of all covariates strictly in accordance in signs, and comparable in magnitudes and relative importance. These consistent effects of SBW defoliation and its interaction with stand characteristics across a broad region provide support for the models' general applicability. However, the models also showed some regional differences such that predictions of net growth, regular mortality (without the influence of SBW defoliation), and ingrowth were generally higher, while predictions of irregular mortality (under the influence 
478 of SBW defoliation) were generally lower for New Brunswick. These differences could 479 reflect general differences in age, composition, and productivity of forests between these regions. More variation in stand dynamics tended to be explained by the models for New Brunswick, which may be related to the stratification applied in its sampling process such that differences in stand dynamics were likely to be more substantial among strata of more distinct stand, site, and defoliation conditions.

Overall, our results strongly demonstrated that even relatively low levels of cumulative defoliation were significantly related to mortality and ingrowth, while net growth was primarily competition driven. Defoliation level and species composition largely determined differences in mortality and ingrowth between Maine and New Brunswick, while site potential productivity and topographic characteristics had little influence. This study clearly highlights the variability in net growth, mortality, and ingrowth following SBW defoliation and suggests that an improved understanding at the individual tree-level may be necessary to fully understand this variability (e.g., Chen et al. 2017). Fully evaluating the developed models from this analysis during the next SBW outbreak will be an important test of their overall representativeness.

\section{Acknowledgments}

Data for this project were provided by the University of Maine Cooperative Forestry Research Unit and Canadian Forest Service. Thanks to Dr. Thomas Brann for providing access to the Maine data. Funding for the project was provided by the Northeastern States Research Cooperative, University of Maine School of Forest Resources, and Maine Agricultural and Forest Experiment Station. Special thanks to Dr. Robert Seymour and several anonymous reviewers for providing feedback on a previous draft. 


\section{References}

Achen, C.H. 1982. Interpreting and using regression. Sage, Beverly Hills, CA.

Baskerville, G.L., and MacLean, D.A. 1979. Budworm-caused mortality and 20-year recovery in immature balsam fir stands. Can. For. Serv. Marit. For. Res. Cent. Inf. Rep. M-X102. Fredericton, NB.

Blais, J.R. 1958. The vulnerability of balsam fir to spruce budworm attack in northwestern Ontario, with special reference to the physiological age of the tree. Forestry Chronicle 34(4): 405-422. doi:10.5558/tfc34405-4.

Blais, J.R. 1983. Trends in the frequency, extent, and severity of spruce budworm outbreaks in eastern Canada. Canadian Journal of Forest Research 13(4): 539-547. doi:10.1139/x83079.

Bonnor, G.M. 1982. Canada's forest inventory 1981. Department of the Environment, Canadian Forest Service, Forestry Statistics and Systems Branch. Ottawa, Canada.

Brann, T.B., Reams, G.A., and Solomon, D.S. 1985. Spruce budworm growth impact study 1982 report. University of Maine, Cooperative Forestry Research Unit. Research Note 15. Orono, ME.

Chen, C., Weiskittel, A., Bataineh, M., and MacLean, D.A. 2017. Evaluating the influence of varying levels of spruce budworm defoliation on annualized individual tree growth and mortality in Maine, USA and New Brunswick, Canada. Forest Ecology and Management 396: 184-194.

Colford-Gilks, A.K., MacLean, D.A., Kershaw Jr., J.A., and Béland, M. 2012. Growth and mortality of balsam fir- and spruce-tolerant hardwood stands as influenced by stand characteristics and spruce budworm defoliation. Forest Ecology and Management 280: 82-92. 
doi:10.1016/j.foreco.2012.05.023.

Erdle, T.A. and MacLean, D.A. 1999. Stand growth model calibration for use in forest pest impact assessment. Forestry Chronicle 75(1): 141-152. doi:10.5558/tfc75141-1.

Ferwerda, J.A., LaFlamme, K.J., Kalloch, Jr., N.R., and Rourke, R.V. 1997. The soils of Maine [online]. Available from $\underline{\text { http://digitalcommons.library.umaine.edu/cgi/viewcontent.cgi? article }=1001 \& \text { context }=\text { aes mi }}$ screports [accessed 16 September 2015].

Fraver, S., Seymour, R.S., Speer, J.H., and White, A.S. 2007. Dendrochronological reconstruction of spruce budworm outbreaks in northern Maine, USA. Canadian Journal of Forest Research 37(3): 523-523. doi:10.1139/X06-251.

Hennigar, C.R., MacLean, D.A., Quiring, D.T., and Kershaw, J.A. Jr. 2008. Differences in spruce budworm defoliation among balsam fir and white, red, and black spruce. Forest Science 54: 158-166.

Hennigar, C.R., MacLean, D.A., Erdle, T.A., and Wagner, R. 2013. Potential spruce budworm impacts and mitigation opportunities in Maine. University of Maine, Cooperative Forestry Research Unit. Orono, ME.

Hennigar, C., Weiskittel, A., Allen, H.L., and MacLean, D.A. 2017. Development and evaluation of a novel biomass increment-based index for site productivity for the Acadian Forest Region. Canadian Journal of Forest Research 47: 400-410.

Irland, L.C., Dimond, J.B., Stone, J.L., Falk, J., and Baum, E. 1988. The spruce budworm outbreak in Maine in the 1970's: assessments and directions for the future [online]. Available from http://maineforest.org/wpcontent/uploads/2013/07/The-Spruce-Budworm-Outbreak-inMaine-in-the-1970s.pdf [accessed 16 September 2015]. 
Kulman, H.M., 1971. Effects of insect defoliation on growth and mortality of trees. Annual Review of Entomology 16(1): 289-324.

Li, R., Weiskittel, A., Dick, A.R., Kershaw, J.A., and Seymour, R.S. 2012. Regional stem taper equations for eleven conifer species in the Acadian region of North America:

Development and assessment. Northern Journal of Applied Forestry 29(1): 5-14. doi:10.5849/njaf.10-037.

MacLean, D.A. 1979. Spruce budworm-caused balsam fir mortality on the Cape Breton Highlands 1974-1978. Canadian Forestry Service, Maritimes Forest Research Centre. Inf. Rep. No. M-X-97. Fredericton, New Brunswick.

MacLean, D.A. 1980. Vulnerability of fir-spruce stands during uncontrolled spruce budworm outbreaks: a review and discussion. Forestry Chronicle 56(5): 213-221.

doi:10.5558/tfc56213-5.

MacLean, D.A. 2016. Impacts of insect outbreaks on tree mortality, productivity, and stand development. Canadian Entomologist 148: S138-S159.

MacLean, D.A. and Erdle, T.A. 1986. Development of relationships between spruce budworm defoliation and forest stand increment in New Brunswick. In: Environmental influences on tree and stand increment, Solomon, D. S., and Brann, T. B. (Eds.). Maine Agric. Exp. Sta. Misc. Publ. 691. Orono, ME. pp. 106-115.

MacLean, D.A., Hunt, T.L., Eveleigh, E. S., and Morgan, M.G. 1996. The relation of balsam fir volume increment to cumulative spruce budworm defoliation. Forestry Chronicle 72(5): $533-540$.

MacLean, D.A., Kline, A.W., and Lavigne, D.R. 1984. Effectiveness of spruce budworm spraying in New Brunswick in protecting the spruce component of spruce-fir stands. 
Canadian Journal of Forest Research 14(2): 163-176. doi:10.1139/x84-033.

MacLean, D.A., and MacKinnon, W.E. 1997. Effects of stand and site characteristics on susceptibility and vulnerability of balsam fir and spruce to spruce budworm in New Brunswick. Canadian Journal of Forest Research 27(11): 1859-1871. doi:10.1139/cjfr-27-111859.

MacLean, D.A. and Ostaff, D.P. 1989. Patterns of balsam fir mortality caused by an uncontrolled spruce budworm outbreak. Canadian Journal of Forest Research 19(9): 10871095. doi:10.1139/x89-165.

McWilliams, W.H., Butler, B.J., Caldwell, L.E., Griffith, D.M., Hoppus, M.L., Laustsen, K.M., Lister, A.J., Lister, T.W., Metzler, J.W., Morin, R.S., Sader, S.A., Stewart, L.B., Steinman, J.R., Westfall, J.A., Williams, D.A., Whitman, A., and Woodall, C.W. 2005. The forests of Maine: 2003. U.S. Dept. of Agriculture, Forest Service, Northeastern Research Station. Report No. 164. Newtown Square, PA.

Myers, C.C., and Beers, T.W. 1968. Point sampling for forest growth estimation. Journal of Forestry 66(12): 927-929.

Osawa, A., Spies, C.J., Diamond, J.B. 1986. Patterns of tree mortality during an uncontrolled spruce budworm outbreak in Baxter State Park, 1983. University of Maine, Maine Agricultural Experiment Station. Tech. Bull. 121. Orono, ME.

Ostaff, D.P. and MacLean, D.A. 1989. Spruce budworm populations, defoliation, and changes in stand condition during an uncontrolled spruce budworm outbreak on Cape Breton Island, Nova Scotia. Canadian Journal of Forest Research 19(9): 1077-1086. doi:10.1139/x89-164.

Piene, H. 1989. Spruce budworm defoliation and growth loss in young balsam fir: Defoliation 
in spaced and unspaced stands and individual tree survival. Canadian Journal of Forest Research 19(10): 1211-1217. doi:10.1139/x89-185.

Pinheiro J., Bates D., DebRoy S., Sarkar D., and R Core Team. 2016. nlme: Linear and nonlinear mixed effects models. [online]. Available from http://CRAN.Rproject.org/package $=$ nlme $[$ accessed 5 December 2016].

Pothier, D., Mailly, D., and Tremblay, S. 2005. Predicting balsam fir growth reduction caused by spruce budworm using large-scale historical records of defoliation. Annals of Forest Science 62(3): 261-267. doi:10.1051/forest:2005018.

Pothier, D., Elie, J.G., Auger, I., Mailly, D., and Gaudreault, M. 2012. Spruce budwormcaused mortality to balsam fir and black spruce in pure and mixed conifer stands. Forest Science 58(1): 24-33.

Power, K., and Gillis, M. 2006. Canada's forest inventory 2001. Natural Resources Canada, Canadian Forest Service, Pacific Forestry Centre. Information Report BC-X-408. Victoria, Canada.

R Development Core Team. 2015. R: A language and environment for statistical computing. R Foundation for Statistical Computing, Vienna, Austria. ISBN 3-900051-07-0. Available online: http://www.r-project.org/ [accessed 16 September 2015].

Reams, G.A., Brann, T.B., and Halteman, W.A. 1988. A nonparametric survival model for balsam fir during a spruce budworm outbreak. Canadian Journal of Forest Research 18(6): 789-795.

Rees, H.W., Fahmy, S.H., Wang, C., and Wells, R.E. 2005. Soils of central and northern New Brunswick. Agriculture and Agri-Food Canada, Potato Research Centre, Research Branch. New Brunswick Soil Survey Report No.: 12. Fredericton, NB. 
Robinson, A.P., and Wykoff, W.R. 2004. Imputing missing height measures using a mixedeffects modeling strategy. Canadian Journal of Forest Research 34(12): 2492-2500. doi:10.1139/x04-137.

Seegrist, D.W., and Arner, S.L. 1982. Mortality of spruce and fir in Maine in 1976-78 due to the spruce budworm outbreak. U.S. Dept. of Agriculture, Forest Service, Northeastern Forest Experiment Station. Research Paper NE-491. Radnor, PA.

Solomon, D.S., and Brann, T.B. 1992. Ten-year impact of spruce budworm on spruce-fir forests of Maine. U.S. Dept. of Agriculture, Forest Service, Northeastern Forest Experiment Station. General Technical Report NE-165. Radnor, PA.

Solomon, D.S., Zhang, L., Brann, T.B., and Larrick, D.S. 2003. Mortality patterns following spruce budworm infestation in unprotected spruce-fir forests in Maine. Northern Journal of Applied Forestry 20(4): 148-153.

Stage, A.R. 1976. An expression for the effect of aspect, slope, and habitat type on tree growth. Forest Science 22(4): 457-460.

Sterner, T.E., and Davidson, A.G. 1982. Forest insect and disease conditions in Canada 1981. Canada. Environment Canada, Canadian Forestry Service. FIDS Report. Ottawa, ON.

USDA. 2010. Wood handbook: Wood as an engineering material. USDA, Forest Service, Forest Products Laboratory. Gen. Tech. Rep. FPL-GTR-190. Madison, WI.

USDA Forest Service. 2009. Major forest insect and disease conditions in the United States 2007. Forest Health Protection Report FS-919. Washington, DC.

Weiskittel, A., and Li, R. 2012. Development of regional taper and volume equations: hardwood species. In: Roth, B.E. (ed.). Cooperative Forestry Research Unit: 2011 Annual 
Report. University of Maine. Orono, ME. pp. 76-84.

Weiskittel, A.R., Hann, D.W., Kershaw Jr, J. A., and Vanclay, J. K. 2011a. Forest growth and yield modeling. Wiley, Hoboken, NJ.

Weiskittel, A.R., Wagner, R.G., and Seymour, R.S. 2011b. Refinement of the Forest Vegetation Simulator, Northeastern Variant growth and yield model: Phase 2. In: Mercier, W. (ed.) Cooperative Forestry Research Unit: 2010 Annual Report. University of Maine. Orono, ME. pp. 23-30.

Woodall, C.W., Miles, P.D., and Vissage, J.S. 2005. Determining maximum stand density index in mixed species stands for strategic-scale stocking assessments. Forest Ecology and Management 216(1): 367-377. doi:10.1016/j.foreco.2005.05.050. 
Table 1. Parameter estimates with corresponding standard errors (SE) and p-values, and model fit statistics of the annual volume net growth models $\left(\mathrm{m}^{3} \mathrm{ha}^{-1} \mathrm{yr}^{-1}\right)$ by region, where $\mathrm{RD}$ is relative density; BF, BS, RS, WS, and HW are proportions of balsam fir, black spruce, red spruce, white spruce, and hardwood in volume, respectively; $\mathrm{HT}_{\mathrm{DOM}}$ is dominant height (m); CDEF is cumulative defoliation $(\%)$.

\begin{tabular}{|c|c|c|c|c|c|c|}
\hline \multirow{2}{*}{$\begin{array}{l}\text { Parameter } \\
\text { and Fit Statistic }\end{array}$} & \multicolumn{3}{|c|}{$\begin{array}{c}\text { Maine } \\
(n=3846)\end{array}$} & \multicolumn{3}{|c|}{$\begin{array}{l}\text { New Brunswick } \\
\qquad(n=753)\end{array}$} \\
\hline & Value & SE & p-value & Value & SE & p-value \\
\hline$\beta 1$ (Intercept) & 4.95690 & 0.03553 & $<0.0001$ & 4.69726 & 0.06315 & $<0.0001$ \\
\hline$\beta 2(\mathrm{RD})$ & 2.77830 & 0.07094 & $<0.0001$ & 3.09574 & 0.15507 & $<0.0001$ \\
\hline$\beta 3(\exp (\mathrm{BS}+\mathrm{RS}+\mathrm{WS}) \cdot \mathrm{HW})$ & -0.01351 & 0.00305 & $<0.0001$ & -0.03197 & 0.01253 & 0.0110 \\
\hline$\beta 4\left(\mathrm{HT}_{\mathrm{DOM}}\right)$ & 0.00234 & 0.00013 & $<0.0001$ & 0.00363 & 0.00046 & $<0.0001$ \\
\hline$\beta 5((\mathrm{BS}+\mathrm{RS}+\mathrm{WS}) \cdot \mathrm{CDEF})$ & -0.00007 & 0.00001 & $<0.0001$ & -0.00013 & 0.00008 & 0.0984 \\
\hline$\beta 6(\mathrm{BF})$ & 0.01919 & 0.00414 & $<0.0001$ & 0.04738 & 0.01107 & $<0.0001$ \\
\hline$\beta 7(\mathrm{BF} \cdot \mathrm{CDEF})$ & -0.00011 & 0.00001 & $<0.0001$ & -- & -- & -- \\
\hline$\gamma 1$ (Random effects on $\beta 1)$ & & 0.1524 & & & 0.1617 & \\
\hline $\begin{array}{l}\mathrm{R}^{2} \\
\text { (Fixed effects) }\end{array}$ & 0.64 & & & 0.64 & & \\
\hline $\begin{array}{l}\mathrm{R}^{2} \\
\text { (Incl. random effects) }\end{array}$ & 0.79 & & & 0.88 & & \\
\hline $\begin{array}{l}\text { Mean bias }\left(\mathrm{m}^{3} \mathrm{ha}^{-1} \mathrm{yr}^{-1}\right) \\
\text { (Fixed effects) }\end{array}$ & -0.06 & & & -0.32 & & \\
\hline $\begin{array}{l}\text { Mean bias }\left(\mathrm{m}^{3} \mathrm{ha}^{-1} \mathrm{yr}^{-1}\right) \\
\text { (Incl. random effects) }\end{array}$ & +0.09 & & & +0.07 & & \\
\hline
\end{tabular}


Table 2. Parameter estimates with corresponding standard errors (SE) and p-values, and model fit statistics of the annual volume mortality rate models $\left(\% \mathrm{yr}^{-1}\right)$ by region, where $\mathrm{BF}, \mathrm{BS}, \mathrm{RS}$, and WS are proportions of balsam fir, black spruce, red spruce, and white spruce, respectively; VOL is standing volume $\left(\mathrm{m}^{3} \mathrm{ha}^{-1}\right)$; $\mathrm{HT}_{\mathrm{DOM}}$ is dominant height $(\mathrm{m})$; CDEF is cumulative defoliation (\%).

\begin{tabular}{|c|c|c|c|c|c|c|}
\hline \multirow{2}{*}{$\begin{array}{l}\text { Parameter } \\
\text { and Fit Statistic }\end{array}$} & \multicolumn{3}{|c|}{$\begin{array}{c}\text { Maine } \\
(n=3 \text { 846) }\end{array}$} & \multicolumn{3}{|c|}{$\begin{array}{l}\text { New Brunswick } \\
\qquad(n=753)\end{array}$} \\
\hline & Value & $\mathbf{S E}$ & p-value & Value & SE & p-value \\
\hline$\beta 1$ (Intercept) & -5.1686 & 0.5095 & $<0.0001$ & -2.6356 & 0.1863 & $<0.0001$ \\
\hline$\beta 2(\mathrm{BF} \cdot \mathrm{CDEF})$ & 0.0158 & 0.0018 & $<0.0001$ & 0.0088 & 0.0034 & 0.0095 \\
\hline$\beta 3(\mathrm{VOL})$ & -0.0038 & 0.0006 & $<0.0001$ & -0.0071 & 0.0010 & $<0.0001$ \\
\hline$\beta 4((\mathrm{BS}+\mathrm{RS}+\mathrm{WS}) \cdot \mathrm{CDEF})$ & 0.0149 & 0.0017 & $<0.0001$ & -- & -- & -- \\
\hline$\beta 5\left(\mathrm{HT}_{\mathrm{DOM}}\right)$ & 0.1725 & 0.0273 & $<0.0001$ & -- & -- & -- \\
\hline$\beta 6$ (Intercept) & -1.8256 & 0.1643 & $<0.0001$ & -- & -- & - \\
\hline$\gamma 1$ (Random effects on $\beta 1)$ & & 0.7203 & & & 0.7269 & \\
\hline $\begin{array}{l}\mathrm{R}^{2} \\
\text { (Fixed effects) }\end{array}$ & 0.28 & & & 0.34 & & \\
\hline $\begin{array}{l}\mathrm{R}^{2} \\
\text { (Incl. random effects) }\end{array}$ & 0.47 & & & 0.54 & & \\
\hline $\begin{array}{l}\text { Mean bias (\%) } \\
\text { (Fixed effects) }\end{array}$ & -0.03 & & & +0.05 & & \\
\hline $\begin{array}{l}\text { Mean bias }(\%) \\
\text { (Incl. random effects) }\end{array}$ & -0.10 & & & +0.14 & & \\
\hline
\end{tabular}


Table 3. Parameter estimates with corresponding standard errors (SE) and p-values, and model fit statistics of the annual volume ingrowth rate models $\left(\% \mathrm{yr}^{-1}\right)$ by region, where $\mathrm{BF}, \mathrm{BS}, \mathrm{RS}$, and WS are proportions of balsam fir, black spruce, red spruce, and white spruce respectively; $\mathrm{HT}_{\mathrm{DOM}}$ is dominant height $(\mathrm{m})$; VOL is standing volume $\left(\mathrm{m}^{3} \mathrm{ha}^{-1}\right)$; CDEF is cumulative defoliation (\%).

\begin{tabular}{|c|c|c|c|c|c|c|}
\hline \multirow{2}{*}{$\begin{array}{l}\text { Parameter } \\
\text { and Fit Statistic }\end{array}$} & \multicolumn{3}{|c|}{$\begin{array}{c}\text { Maine } \\
(n=3846)\end{array}$} & \multicolumn{3}{|c|}{$\begin{array}{l}\text { New Brunswick } \\
\qquad(n=753)\end{array}$} \\
\hline & Value & SE & p-value & Value & SE & p-value \\
\hline$\beta 1$ (Intercept) & -1.0239 & 0.1841 & $<0.0001$ & -4.1678 & 0.2683 & $<0.0001$ \\
\hline$\beta 2(\mathrm{BF} \cdot \mathrm{CDEF})$ & -0.0063 & 0.0023 & 0.0063 & -0.0062 & 0.0040 & 0.1251 \\
\hline$\beta 3\left(\mathrm{HT}_{\mathrm{DOM}}\right)$ & -0.1400 & 0.0171 & $<0.0001$ & -- & -- & - \\
\hline$\beta 4(\mathrm{VOL})$ & -0.0110 & 0.0015 & $<0.0001$ & -0.0050 & 0.0017 & 0.0033 \\
\hline$\beta 5(\mathrm{BS}+\mathrm{RS}+\mathrm{WS})$ & -0.6455 & 0.1977 & 0.0011 & -- & -- & - \\
\hline$\gamma 2$ (Random effects on $\beta 2$ ) & & 0.0085 & & & $<0.0001$ & \\
\hline$\gamma 4$ (Random effects on $\beta 4)$ & & 0.0065 & & & 0.0039 & \\
\hline $\begin{array}{l}\mathrm{R}^{2} \\
\text { (Fixed effects) }\end{array}$ & 0.20 & & & 0.21 & & \\
\hline $\begin{array}{l}\mathrm{R}^{2} \\
\text { (Incl. random effects) }\end{array}$ & 0.33 & & & 0.37 & & \\
\hline $\begin{array}{l}\text { Mean bias (\%) } \\
\text { (Fixed effects) }\end{array}$ & -0.04 & & & +0.07 & & \\
\hline $\begin{array}{l}\text { Mean bias }(\%) \\
\text { (Incl. random effects) }\end{array}$ & $\sim 0.00$ & & & +0.13 & & \\
\hline
\end{tabular}




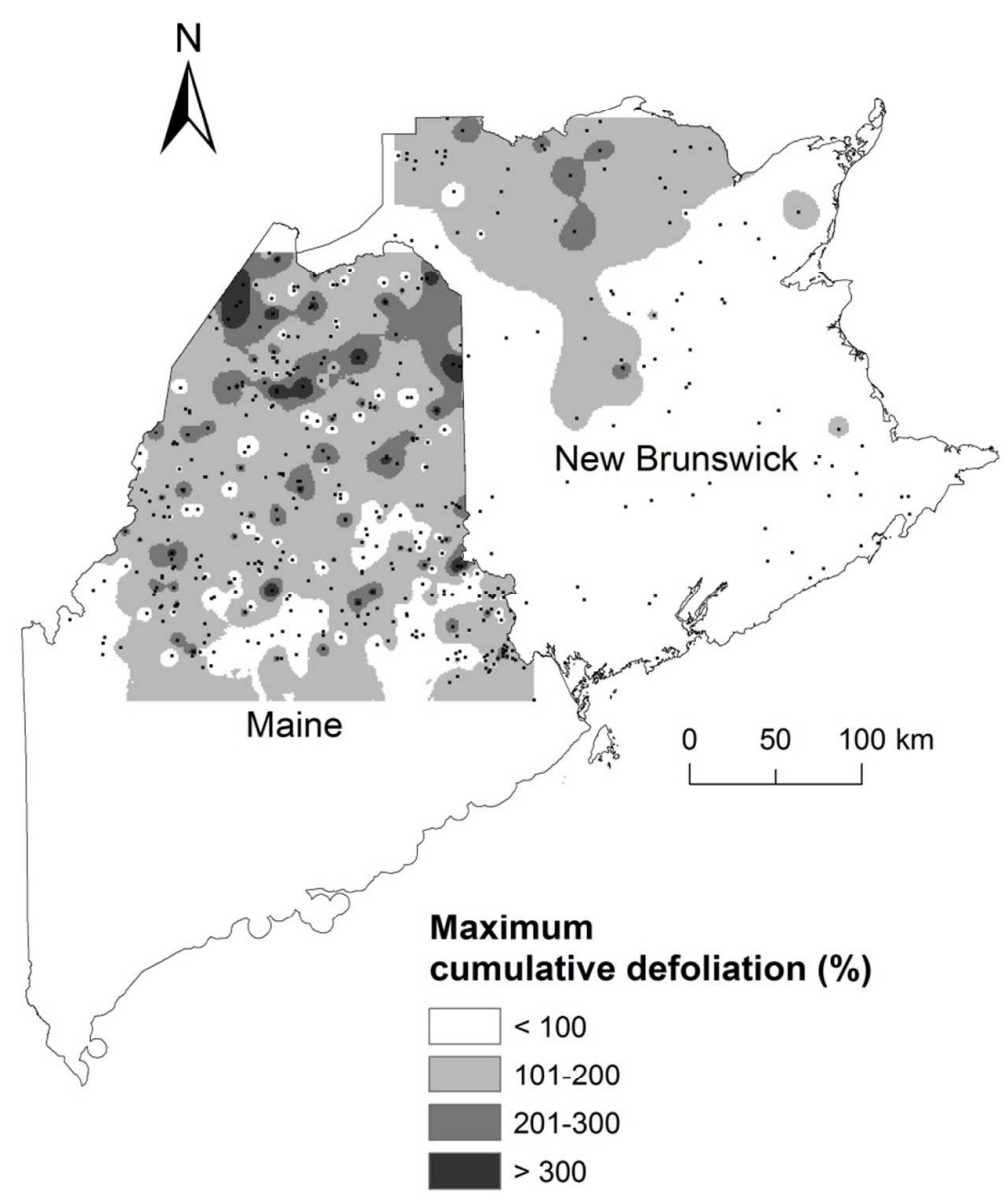

Figure 1. Locations of the study area and sample plots included in this analysis with interpolated plot-level maximum cumulative defoliation (cumulative sums of the percentage defoliation of current-year foliage from all previous years until current year; \%). Data collected in Maine during 1975-1985 covered most of the temporal extent of the last SBW outbreak, while the New Brunswick analysis period of 1986-1991 was in the declining years of the SBW outbreak. 

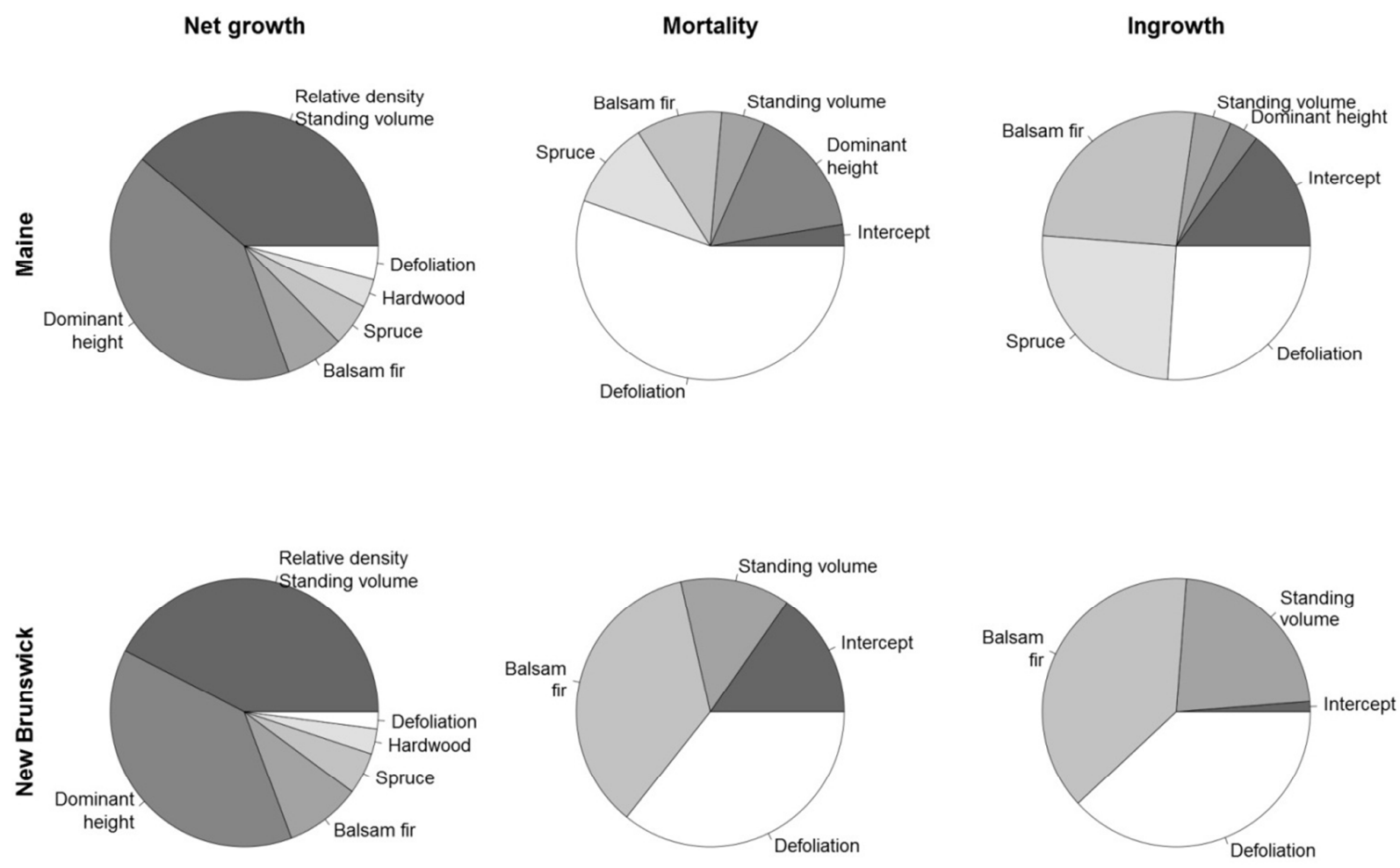

Figure 2. Relative importance of various variables (at their mean values; Achen 1982) on different stand dynamic components examined in this analysis (net growth, mortality, ingrowth) by region. 


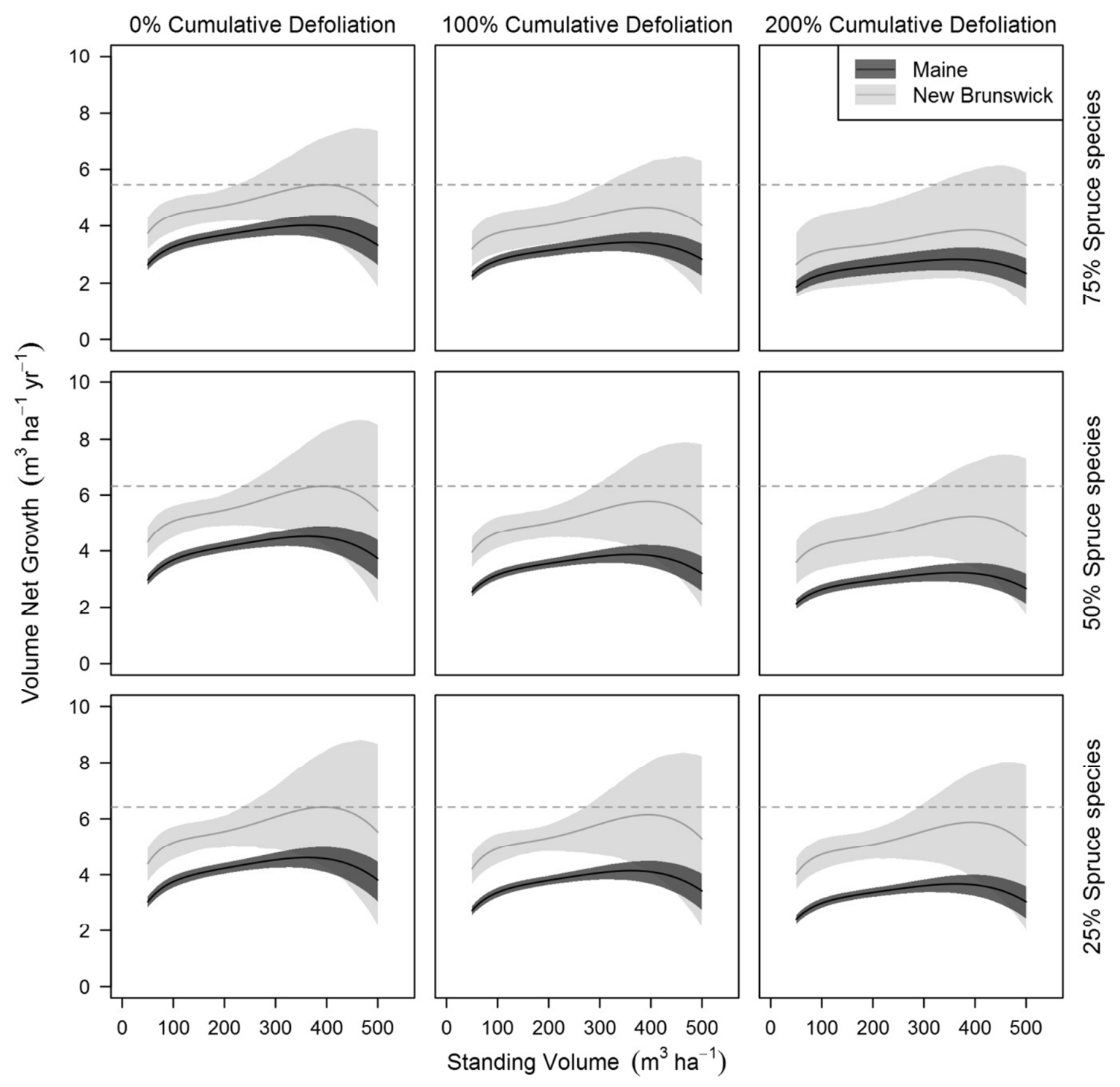

Figure 3. Predictions of annual volume net growth $\left(\mathrm{m}^{3} \mathrm{ha}^{-1} \mathrm{yr}^{-1}\right)$ as a function of standing volume $\left(\mathrm{m}^{3}\right.$ $\mathrm{ha}^{-1}$ ) under different levels of cumulative defoliation and spruce species content by region. All the other covariates were set at their mean values except relative density was set based on its correlation with standing volume. The observed net growth was closest to that shown in the lower-left graph. Dashed lines that pass the maxima of the curves in the first column from left are used to help show the differences in growth under different levels of defoliation. The shaded areas are the $95 \%$ confidence interval of the predictions. 


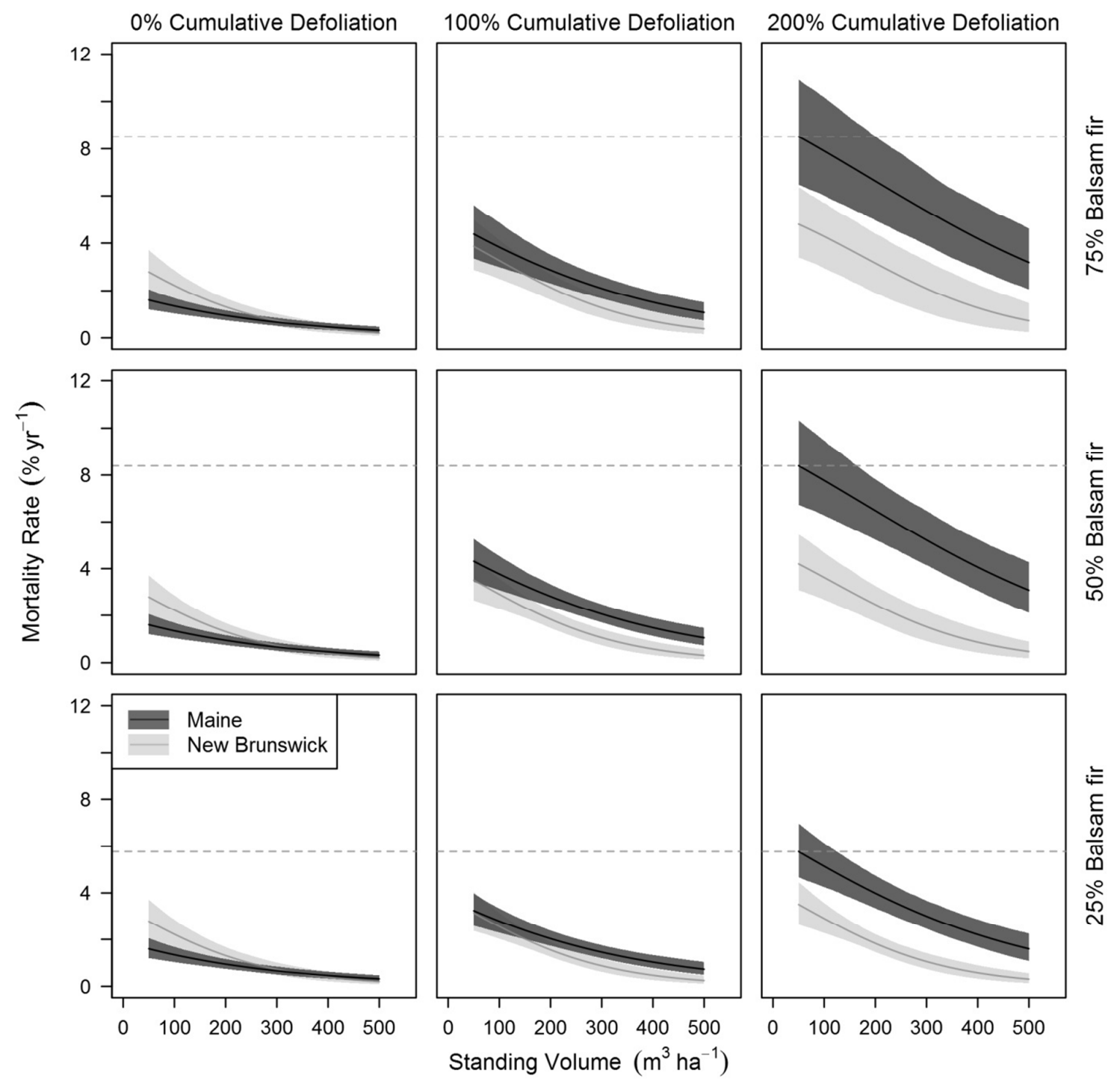

Figure 4. Predictions of volume mortality rate $\left(\% \mathrm{yr}^{-1}\right)$ as a function of standing volume $\left(\mathrm{m}^{3} \mathrm{ha}^{-1}\right)$ under different levels of cumulative defoliation and balsam fir content by region. All the other covariates were set at their mean values. The observed mortality was closest to that shown in the lower-left graph. Dashed lines that pass the maxima of the curves in the third column from left are used to help show the differences in mortality rate under different levels of defoliation. The shaded areas are the $95 \%$ confidence interval of the predictions. 


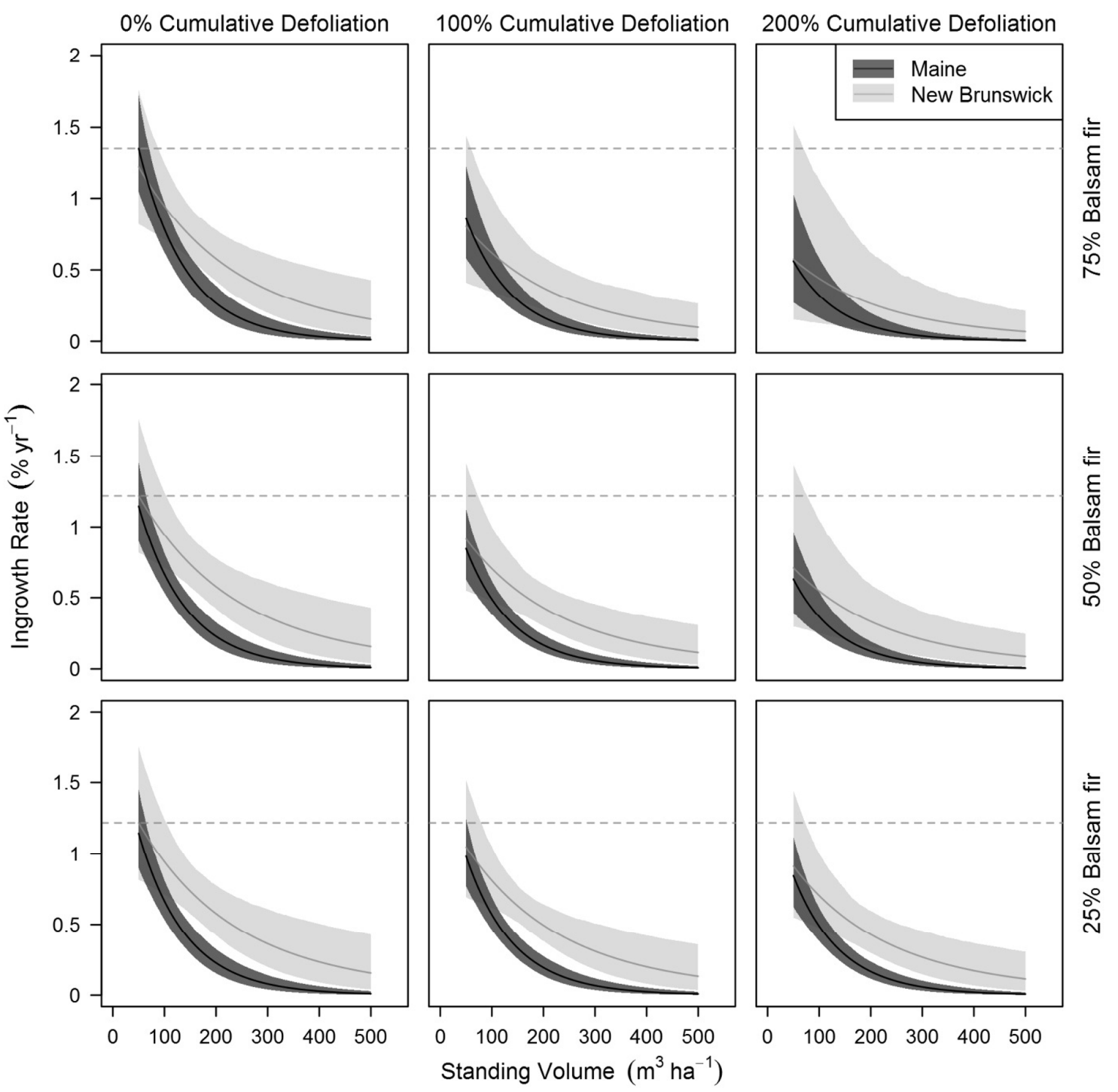

Figure 5. Predictions of volume ingrowth rate $\left(\% \mathrm{yr}^{-1}\right)$ as a function of standing volume $\left(\mathrm{m}^{3} \mathrm{ha}^{-1}\right)$ under different levels of cumulative defoliation and balsam fir content by region. All the other covariates were set at their mean values. The observed ingrowth was closest to that shown in the lower-left graph. Dashed lines that pass the maxima of the curves in the first column from left are used to help show the differences in ingrowth rate under different levels of defoliation. The shaded areas are the $95 \%$ confidence interval of the predictions. 


\section{Supplemental Materials}

\section{S1. Temporal variation in defoliation}

The following graph presents how annual SBW defoliation changed at each of our sample plots over time, where each line represents one sample plot and $\mathrm{n}$ is the year that defoliation peaked at this sample plot. It shows that there is a large amount of temporal variation in defoliation. Despite this variation, there is a rather clear pattern such that defoliation rises, peaks, and declines rapidly, and unlikely remains at high levels over time in contrary to some previous assumptions (Intermittent insecticide spraying at different locations may also have contributed to this pattern). In addition, the graph indicates that New Brunswick was mainly in the later phase of the SBW outbreak.
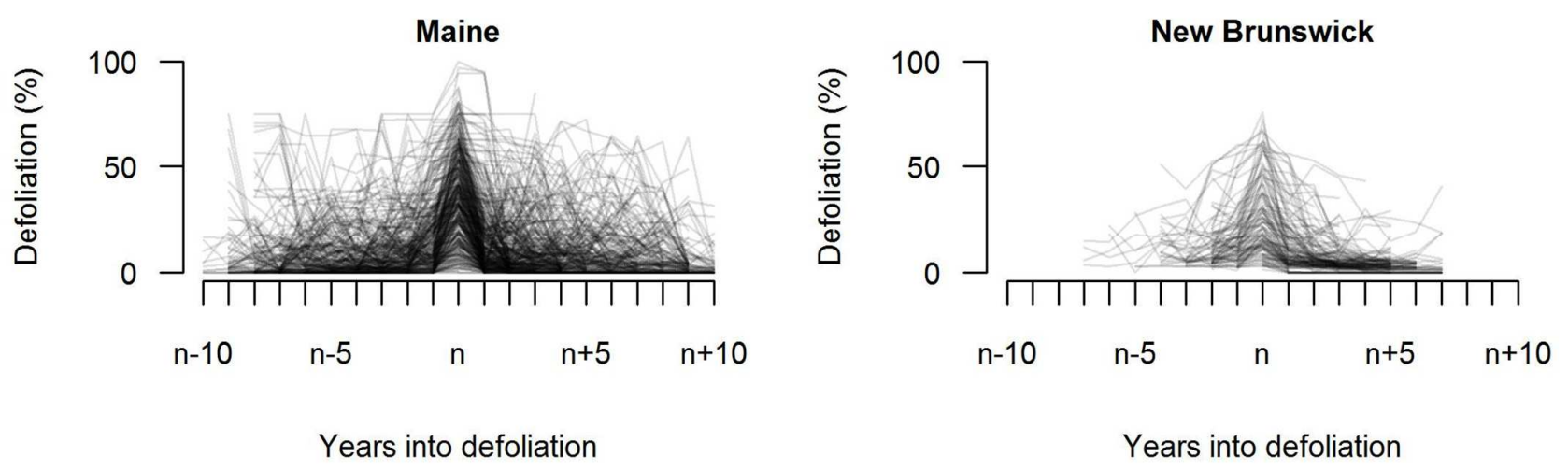
S2. The effects of insecticide spraying on the stand growth components

The following graph compares stand growth components of net growth, mortality, and ingrowth between sample plots with and without insecticide spraying in Maine during the last spruce budworm (SBW) outbreak, and shows that the effects of insecticide spraying were minimal and not significant. MacLean et al. (1984) also found that spraying did not result in significant difference in mortality rates of black, red spruce, and their hybrids in New Brunswick. However, since spraying was more likely to be applied to areas facing higher defoliation pressure, it was possible that such areas would otherwise have been more influenced by SBW defoliation without the protection of spraying.

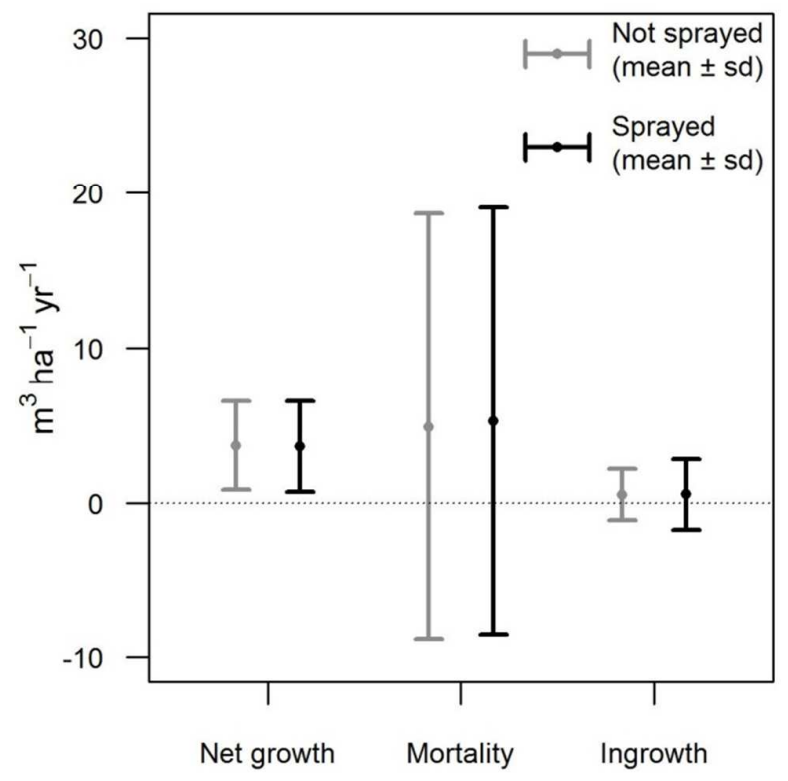


S3. A summary of the data

A summary of the attributes derived from the data used in this analysis is shown in the following table. 


\begin{tabular}{|c|c|c|c|c|c|c|c|c|c|c|}
\hline \multirow[b]{2}{*}{ Attributes } & \multicolumn{5}{|c|}{ Maine $(n=3$ 846) } & \multicolumn{5}{|c|}{ New Brunswick $(n=753)$} \\
\hline & Mean & Median & SD & Min. & Max. & Mean & Median & SD & Min. & Max. \\
\hline Net growth $\left(\mathrm{m}^{3}\right.$ ha $^{-1}$ year $\left.^{-1}\right)$ & 3.70 & 3.09 & 2.88 & 0.00 & 41.13 & 5.36 & 4.93 & 3.36 & 0.00 & 55.32 \\
\hline Mortality $\left(\mathrm{m}^{3} \mathrm{ha}^{-1}\right.$ year $\left.^{-1}\right)$ & 4.96 & 0.00 & 13.76 & 0.00 & 231.68 & 3.11 & 0.00 & 5.85 & 0.00 & 59.73 \\
\hline Mortality rate in volume $\left(\%\right.$ year $\left.^{-1}\right)$ & 2.42 & 0.00 & 7.03 & 0.00 & 100.00 & 1.69 & 0.00 & 3.55 & 0.00 & 44.64 \\
\hline Ingrowth $\left(\mathrm{m}^{3} \mathrm{ha}^{-1}\right.$ year $\left.^{-1}\right)$ & 0.53 & 0.00 & 1.76 & 0.00 & 40.20 & 0.80 & 0.00 & 2.62 & 0.00 & 43.42 \\
\hline Ingrowth rate in volume $\left(\%\right.$ year $\left.{ }^{-1}\right)$ & 0.40 & 0.00 & 2.27 & 0.00 & 82.52 & 0.47 & 0.00 & 1.49 & 0.00 & 20.34 \\
\hline Standing volume $\left(\mathrm{m}^{3} \mathrm{ha}^{-1}\right)$ & 224.58 & 214.56 & 112.00 & 1.93 & 625.78 & 193.89 & 190.46 & 69.23 & 23.61 & 393.60 \\
\hline Stand density index & 583.17 & 586.79 & 237.20 & 15.73 & 1394.51 & 618.62 & 622.33 & 186.14 & 97.19 & 1226.12 \\
\hline Relative density & 0.30 & 0.30 & 0.12 & 0.01 & 0.66 & 0.30 & 0.30 & 0.09 & 0.05 & 0.61 \\
\hline Dominant height (m) & 19.23 & 19.20 & 2.85 & 6.71 & 28.04 & 17.93 & 17.61 & 3.00 & 12.64 & 31.97 \\
\hline Cumulative defoliation (\%) & 84.98 & 58.51 & 86.36 & 0.00 & 585.63 & 64.28 & 47.18 & 53.50 & 5.31 & 321.87 \\
\hline Proportion of balsam fir in volume & 0.26 & 0.21 & 0.24 & 0.00 & 1.00 & 0.33 & 0.30 & 0.24 & 0.00 & 0.89 \\
\hline Proportion of white spruce in volume & 0.03 & 0.00 & 0.11 & 0.00 & 1.00 & 0.09 & 0.04 & 0.14 & 0.00 & 0.78 \\
\hline Proportion of black spruce in volume & 0.03 & 0.00 & 0.13 & 0.00 & 1.00 & 0.11 & 0.00 & 0.24 & 0.00 & 1.00 \\
\hline Proportion of red spruce in volume & 0.25 & 0.15 & 0.27 & 0.00 & 1.00 & 0.22 & 0.10 & 0.26 & 0.00 & 0.98 \\
\hline Proportion of hardwood in volume & 0.19 & 0.11 & 0.21 & 0.00 & 1.00 & 0.10 & 0.04 & 0.13 & 0.00 & 0.50 \\
\hline Biomass growth index & 1.95 & 2.00 & 0.34 & 0.94 & 2.74 & -- & -- & -- & -- & -- \\
\hline Climate Site Index & 13.47 & 13.37 & 1.37 & 9.23 & 19.03 & 11.63 & 11.59 & 1.26 & 8.61 & 14.90 \\
\hline Wetness Index & 7.27 & 7.37 & 2.86 & 0.75 & 15.84 & 10.60 & 10.61 & 1.49 & 7.07 & 14.02 \\
\hline Slope $(\%)$ & 9.76 & 5.24 & 14.04 & 0.00 & 132.70 & 6.59 & 2.62 & 6.10 & 0.00 & 27.97 \\
\hline Aspect (degree) & 174.00 & 174.51 & 113.11 & 0.00 & 360.00 & 176.20 & 186.34 & 98.17 & 0.00 & 358.80 \\
\hline Elevation (m) & 263.20 & 284.57 & 129.62 & 41.02 & 691.30 & 202.40 & 188.75 & 133.97 & 0.00 & 577.50 \\
\hline
\end{tabular}


S4. Comparisons between our mortality and ingrowth models with zero-one-inflated models

We built zero-one-inflated beta regression models for mortality and ingrowth in the following customary way to compare with our mortality and ingrowth models:

$$
\text { [1] } y=p_{0} \cdot 0+\left(1-p_{0}\right) \cdot\left(1-p_{1}\right) \cdot \mu+\left(1-p_{0}\right) \cdot p_{1} \cdot 1
$$

where $y$ is the proportion of mortality/ingrowth; $p_{0}$ and $\left(1-p_{0}\right) \cdot p_{1}$ are the probabilities of $\mathrm{y}=0$ and $\mathrm{y}=1$, respectively; and $\mu$ is the mean of a beta distribution.

$p_{0}, p_{1}$, and $\mu$ were all modeled through logit link functions, while the precision parameter $\varphi$ of the beta distribution was modeled by a log link function as follows:

$$
\begin{gathered}
\text { [2] } \log \left(\frac{p_{0}}{1-p_{0}}\right)=x_{0} \beta_{0} \\
\text { [3] } \log \left(\frac{p_{1}}{1-p_{1}}\right)=x_{1} \beta_{1} \\
\text { [4] } \log \left(\frac{\mu}{1-\mu}\right)=x \beta \\
\text { [5] } \log (\varphi)=x_{\varphi} \beta_{\varphi}
\end{gathered}
$$

where $x_{0}, x_{1}, x$, and $x_{\varphi}$ are predictors for $p_{0}, p_{1}, \mu$, and $\varphi$, respectively; and $\beta_{0}, \beta_{1}, \beta$, and $\beta_{\varphi}$ are corresponding parameters.

Parameter estimation was conducted in the following Bayesian setting using R package "zoib" (Liu and Kong 2016):

$$
\begin{gathered}
{[6] p\left(\beta_{0}, \beta_{1}, \beta, \beta_{\varphi} \vee y\right)} \\
\propto\left(p_{0}^{I(y=0)} \cdot\left(\left(1-p_{0}\right) \cdot\left(1-p_{1}\right)\right)^{I(0<y<1)} \cdot \operatorname{Beta}(a, b) \cdot\left(\left(1-p_{0}\right) \cdot p_{1}\right)^{I(y=1)}\right) \\
\cdot N\left(0,10^{-3}\right)
\end{gathered}
$$


where $a=\mu \cdot \varphi ; b=(1-\mu) \varphi ; I$ indicates an indicator variable; and $N\left(0,10^{-3}\right)$ is the multivariate normal prior distribution of the parameters.

Different combinations of predictors derived from various tree, stand, and site attributes were tested in Equations [2] - [5]. The root mean squared error (RMSE) of the predictions on mortality using parameters estimated from Equation [6] ranged from 0.0998 (where $x$ comprised only cumulative defoliation; and $x_{0}, x_{1}$, and $x_{\varphi}$ comprised only intercept) to 0.0750 (where $x$ comprised standing volume, relative density, proportion of balsam fir · cumulative defoliation, and proportion of spruce $\cdot$ cumulative defoliation; $x_{0}$ comprised cumulative defoliation and proportion of hardwood; and $x_{1}$, and $x_{\varphi}$ comprised only intercept). In comparison, RMSE of our mortality model was 0.0682 and 0.0584 (with random effects).

More importantly, our model outperformed the above zero-one-inflated beta model in terms of predicting excessive zero and over-dispersed observations. First, our model had 904 close-to-zero predictions $(y<0.01$ when $y=0)$ comparing to 385 the zero-one-inflated beta model has (albeit being named as zero-one-inflated beta model, predicted values of the above specific model obviously cannot be either zero or one). Second, the maximum predicted value of our model is 0.41 , which is 0.23 in the zero-one-inflated beta model.

The following graphs compare the predictions of mortality between the zero-one-inflated beta model and our model. Specifically, Graph A shows that predictions from our model better resembles the distribution of the observed mortality. Graphs A and B both show that our model yields closer predictions of large observed values. Graph C shows that our model has a larger number of close-tozero predictions. In Graphs B and C, x-axis values were jittered by Uniform $(-0.01,0.01)$ and Uniform $(-0.0005,0.0005)$, respectively, to show overlapping observations. 


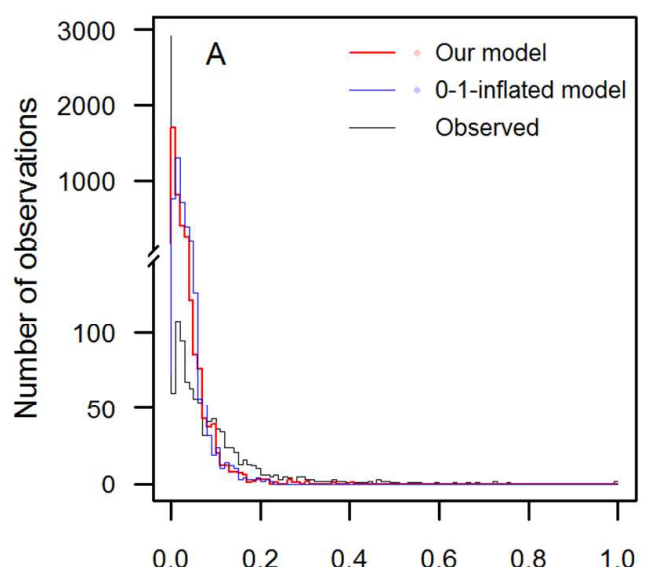

Annual mortality rate

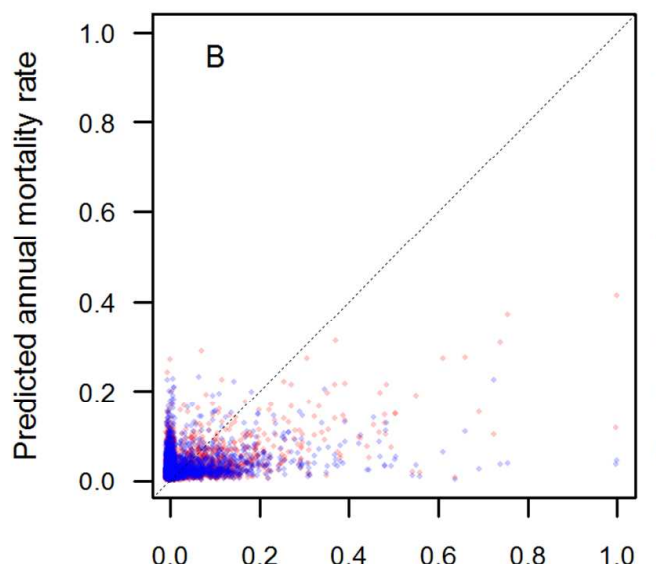

Observed annual mortality rate

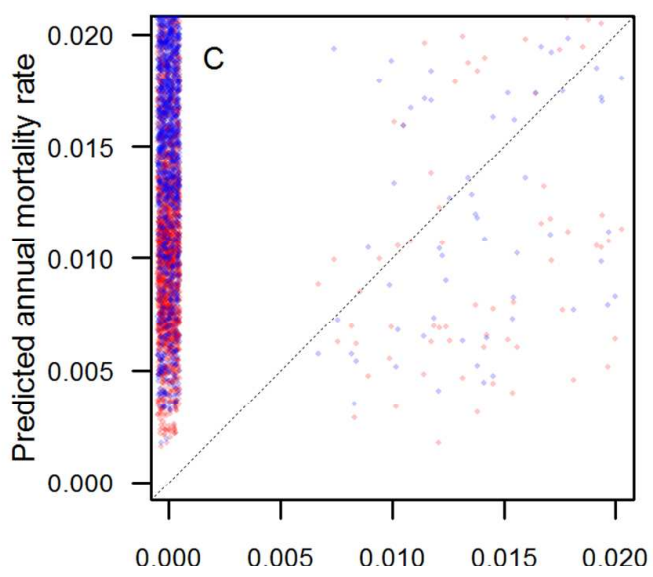

Observed annual mortality rate

Similarly, consistent findings as for mortality in terms of model performance were also found for ingrowth analysis. The minimum RMSE of the predictions on ingrowth from zero-one-inflated beta model was 0.0262 comparing to 0.0233 and 0.0222 (with random effects) of our model.

Overall, we evaluated the more traditional zero-inflated approach and found it to not be superior to our approach. More importantly, our findings in terms of parameter significance and magnitude of influence were consistent with the zero-inflated approach. 
S5. The effects of site characteristics on the stand dynamics examined

Site characteristics represented by the variables of Slope, $\cos ($ Aspect $)$, Slope $\cdot \cos ($ Aspect $)$, Elevation, Wetness index, Climate site index, and Biomass growth index were initially tested in our models. However, none of them yielded significant effects or accounted for more than $1 \%$ of the variation in the response variables in both regions. The following table shows correlations between these characteristics and the response variables (and their residuals) in our models. It demonstrates that the correlations were generally negligible (especially with the residuals) and sometimes contradicting between the two regions. After these tests, dominant height appeared to be a better proxy of site potential productivity than the other covariates mentioned above. Hence, dominant height was used in our models. 


\begin{tabular}{|c|c|c|c|c|c|c|c|}
\hline & Slope & $\cos ($ Aspect $)$ & $\begin{array}{r}\text { Slope } \\
\cdot \cos (\text { Aspect })\end{array}$ & Elevation & $\begin{array}{r}\text { Wetness } \\
\text { index }\end{array}$ & $\begin{array}{l}\text { Climate } \\
\text { site index }\end{array}$ & $\begin{array}{r}\text { Biomass } \\
\text { growth index }\end{array}$ \\
\hline \multicolumn{8}{|c|}{ Maine } \\
\hline Annual net growth & 0.045 & -0.089 & -0.024 & 0.013 & -0.054 & -0.046 & 0.007 \\
\hline $\begin{array}{l}\text { Residuals of } \\
\text { annual net growth }\end{array}$ & -0.003 & 0.074 & 0.009 & 0.013 & -0.078 & -0.003 & -0.015 \\
\hline Annual mortality rates & 0.028 & 0.007 & 0.039 & 0.003 & -0.005 & -0.032 & -0.009 \\
\hline $\begin{array}{l}\text { Residuals of } \\
\text { annual morality rates }\end{array}$ & -0.006 & 0.019 & 0.023 & 0.010 & 0.022 & 0.015 & -0.027 \\
\hline Annual ingrowth rates & 0.006 & -0.014 & -0.025 & -0.040 & -0.023 & -0.012 & 0.056 \\
\hline $\begin{array}{l}\text { Residuals of } \\
\text { annual ingrowth rates }\end{array}$ & 0.027 & -0.041 & 0.019 & 0.009 & 0.007 & 0.002 & 0.015 \\
\hline \multicolumn{8}{|c|}{ New Brunswick } \\
\hline Annual net growth & 0.201 & -0.030 & 0.030 & 0.210 & -0.020 & 0.141 & -- \\
\hline $\begin{array}{l}\text { Residuals of } \\
\text { annual net growth }\end{array}$ & 0.006 & 0.028 & 0.023 & -0.019 & -0.031 & 0.022 & -- \\
\hline Annual mortality rates & 0.037 & 0.030 & -0.041 & -0.009 & 0.013 & -0.003 & -- \\
\hline $\begin{array}{l}\text { Residuals of } \\
\text { annual morality rates }\end{array}$ & 0.047 & -0.036 & 0.011 & -0.008 & 0.051 & 0.018 & -- \\
\hline Annual ingrowth rates & 0.034 & 0.009 & 0.031 & -0.058 & -0.042 & -0.038 & -- \\
\hline $\begin{array}{l}\text { Residuals of } \\
\text { annual ingrowth rates }\end{array}$ & -0.023 & 0.002 & -0.002 & -0.026 & -0.002 & 0.022 & -- \\
\hline
\end{tabular}




\section{S6. The fit of our models}

In addition to the statistics presented in the text and tables, the following graphs illustrate the fit of our models by plotting predicted values of net growth, mortality, and ingrowth over corresponding observed values (a few large observations were truncated to show details in the fit).

For Maine:
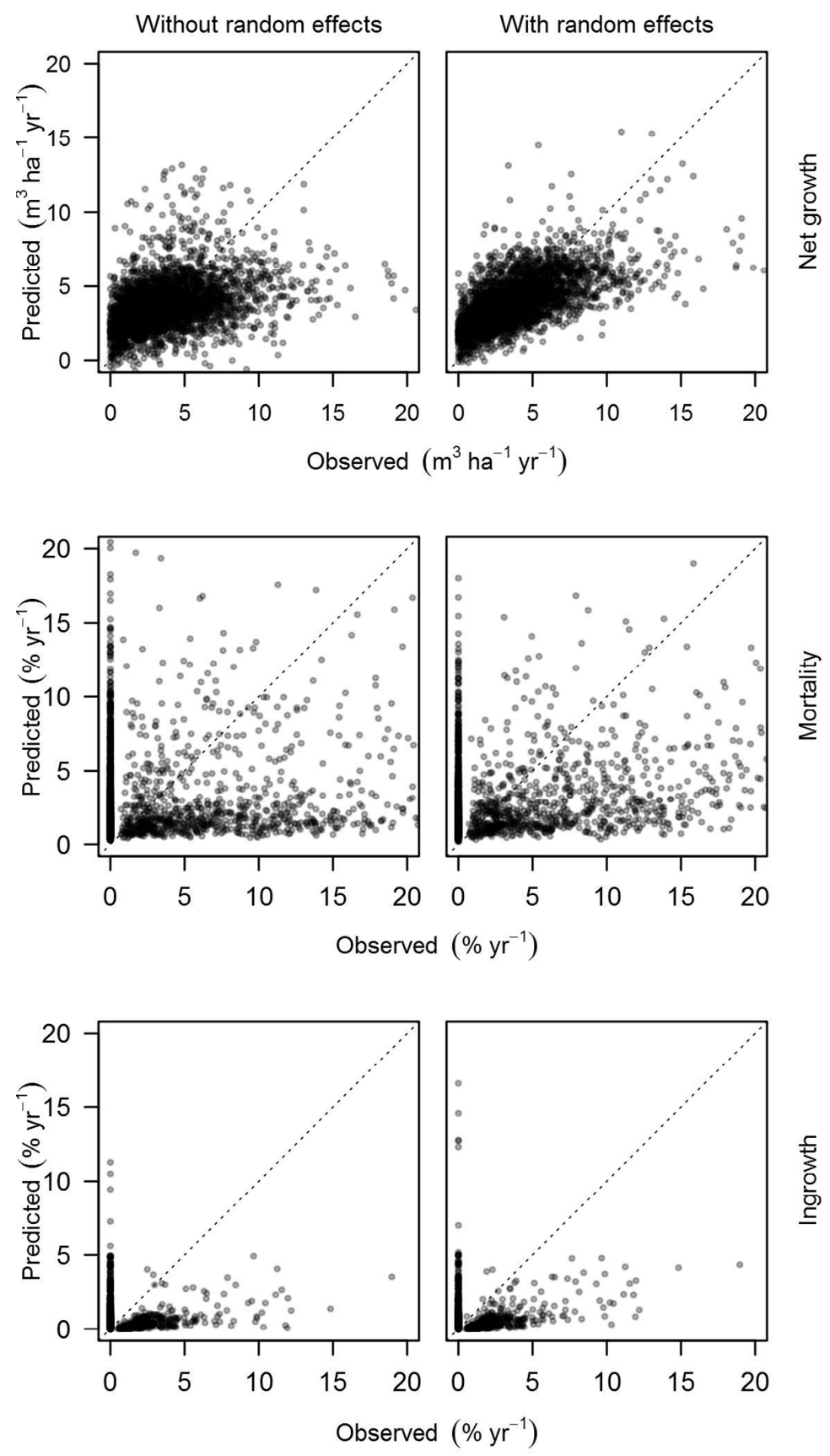
For New Brunswick:
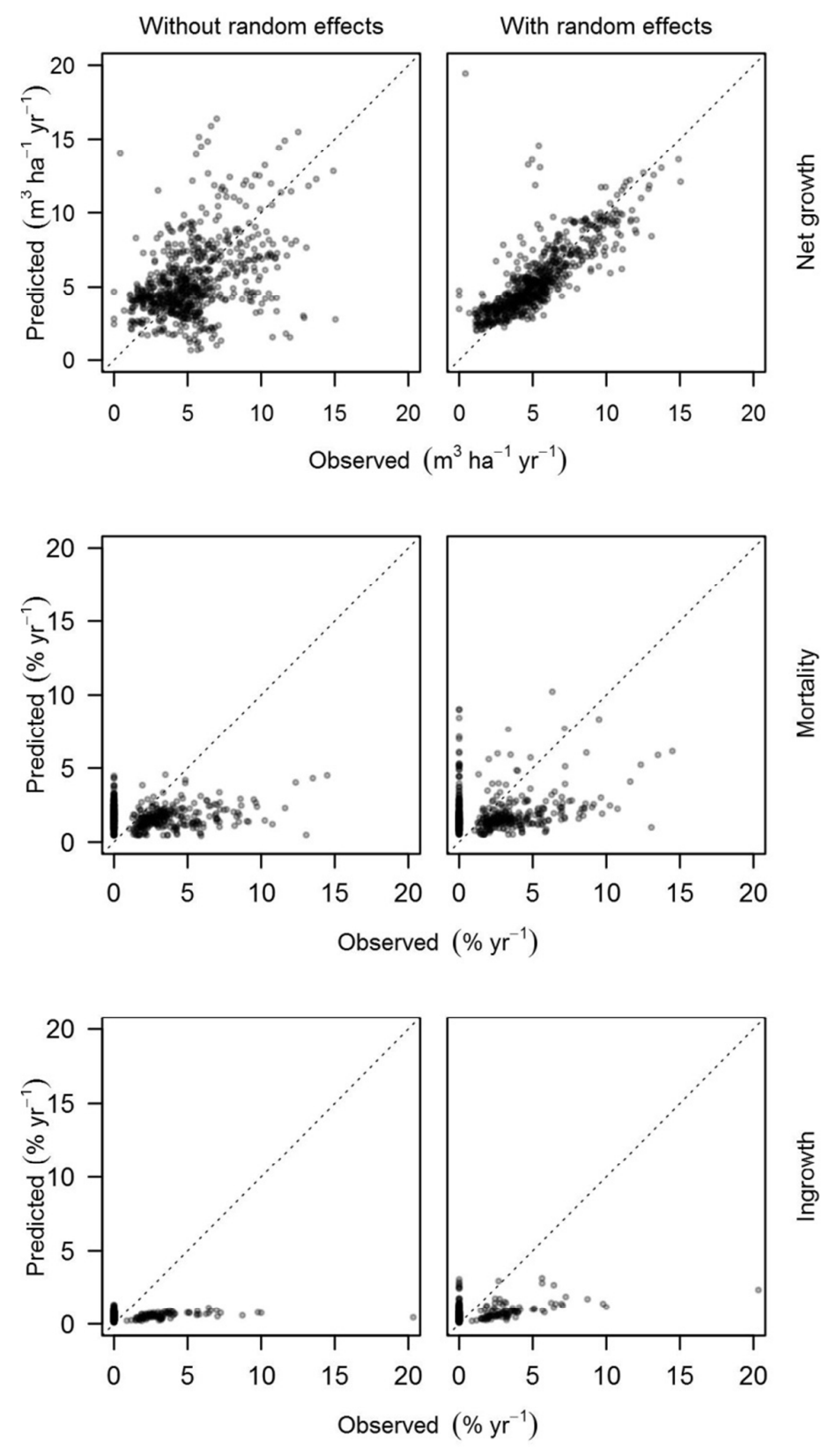
S7. Cumulative mortality probability of different host species

Our data indicated differences in host species' vulnerability to SBW defoliation. The following graph illustrates the observed cumulative mortality probability (\%) over the observed cumulative defoliation (\%) by species. It shows that cumulative mortality probability of red/black spruce surpasses that of balsam fir at high levels of defoliation. Since the beginning part of the SBW outbreak was not recorded, the actual cumulative mortality probability should be stretched to the right for New Brunswick.
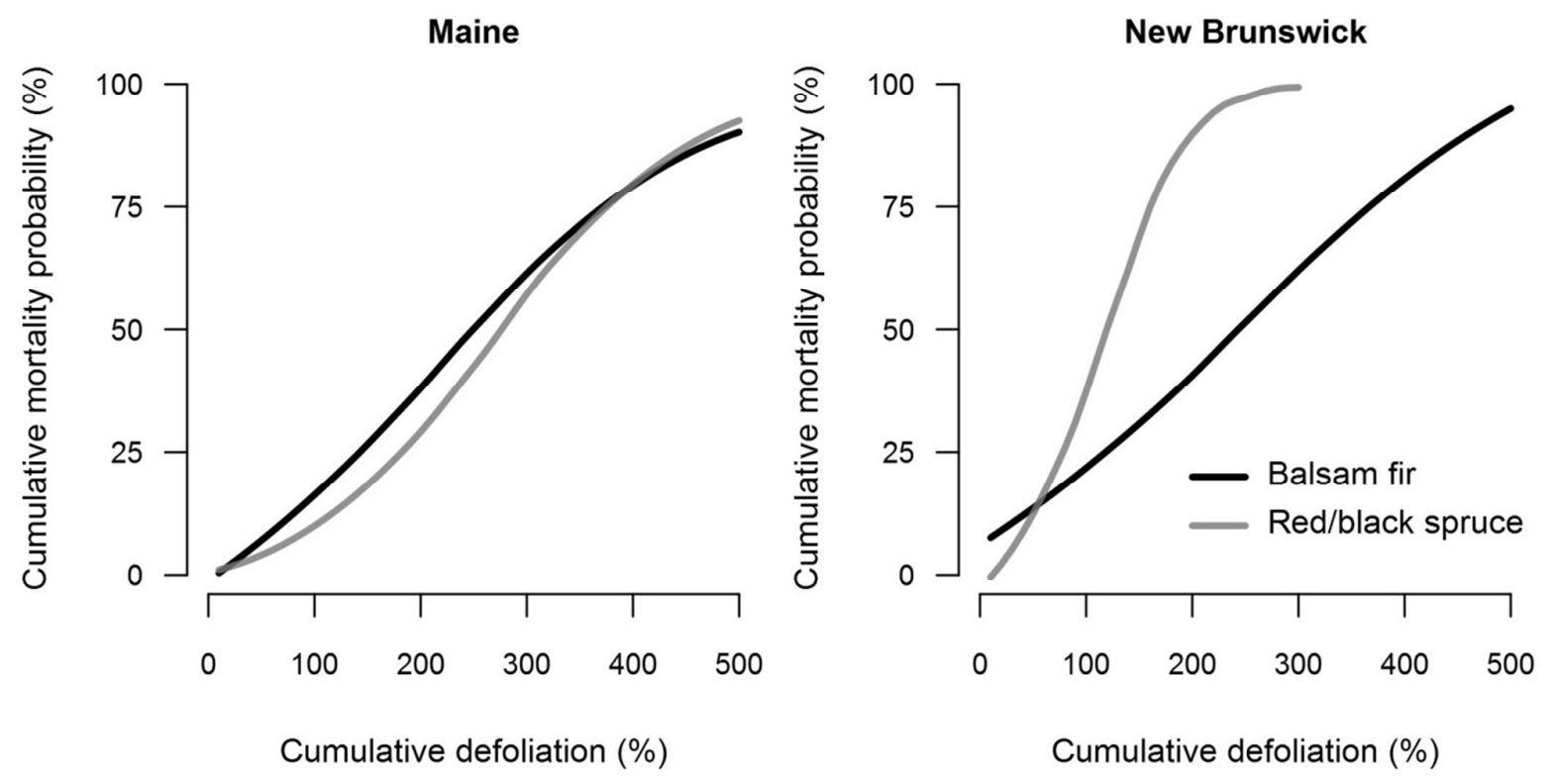


\section{References}

MacLean, D.A., Kline, A.W., and Lavigne, D.R. 1984. Effectiveness of spruce budworm spraying in New Brunswick in protecting the spruce component of spruce-fir stands. Canadian Journal of Forest Research 14(2): 163-176. doi:10.1139/x84-033.

Liu, F. and Kong, Y. 2016. zoib: Bayesian inference for Beta regression and zero-or-one inflated Beta regression [online]. Available from https://CRAN.R-project.org/package=zoib $[$ accessed 5 December 2016]. 